\title{
Characteristics and consequences of flow in the lower crust
}

\author{
Dan $\mathrm{M}^{\mathrm{c}}$ Kenzie, Francis Nimmo, and James A. Jackson \\ Institute of Theoretical Geophysics, Bullard Laboratories of the Department of Earth Sciences \\ University of Cambridge, Cambridge, United Kingdom \\ P.B. Gans \\ Department of Geological Sciences, University of California, Santa Barbara \\ E.L. Miller \\ Department of Geological and Environmental Sciences, Stanford University, Stanford, California
}

\begin{abstract}
In some places, there is strong evidence that the lower continental crust has flowed so as to smooth out variations in crustal thickness caused by differential crustal extension or shortening. In order to better understand the processes involved, we investigate the behavior of a fluid layer over a fluid half-space to see how such a system responds to the deformation of its upper and lower boundaries. This simple system can be used to study both the decay of crustal thickness contrasts and the behavior of a thin lithospheric sheet. The changing response of the system to variations in density and viscosity contrasts and to different boundary conditions imposed on the fluid interface can easily be studied analytically. The most important results are that variations in crustal thickness on a wavelength of a few times the thickness of the flowing channel will decay quickest and that large lateral variations in crustal thickness cause the fluid to develop a steep front, which may cause a topographic step above it at the Earth's surface. Deformation within the channel will be principally by simple shear. The clear association of lower crustal flow with regions of thickened crust and magmatic activity suggests that both can reduce the viscosity of the lower crust to levels at which flow can occur. The smoothing of crustal thickness contrasts leads to differential vertical motions, and is thus a method by which substantial tilting can occur without faulting. This differential uplift may be responsible for rotating and exhuming some of the detachment faults in metamorphic core complexes in the Basin and Range province of the western United States. It is also a method of causing structural inversion in basins that does not require the reactivation of normal faults as thrusts or reverse faults.
\end{abstract}

\section{Introduction}

The success of plate tectonics as a description of oceanic tectonics has encouraged attempts to use the same ideas to describe continental deformation. Such efforts have been partially successful: the relative motion between the large aseismic parts of continents can be usefully described by relative angular velocities. However, the zones of distributed continental deformation that are sometimes more than $2000 \mathrm{~km}$ across cannot be described by rigid motions [e.g., England and Jackson, 1989]. One obvious and important difference between

Copyright 2000 by the American Geophysical Union.

Paper number 1999JB900446.

0148-0227/00/1999JB900446\$09.00 oceanic and continental lithosphere is the thickness of the crust. Differences in crustal thickness produce corresponding variations in elevation and hence of gravitational potential energy. Such forces are more important in continental regions, where the crust is thick, than they are in the oceans and tend to equalize the crustal thickness.

A number of observations of continental deformation suggest that, at least in some places, the brittle deformation of the upper crust is decoupled from the deformation of the lower crust. One example, described by Gans [1987] and illustrated in Figure 1, is from the eastern Basin and Range province of the western United States. Figure 1 shows that variations in the extension factor $\beta$ of the upper crust, from 1.4 to 4.0 , are not associated with corresponding changes in topography or crustal thickness. Although some igneous material is 

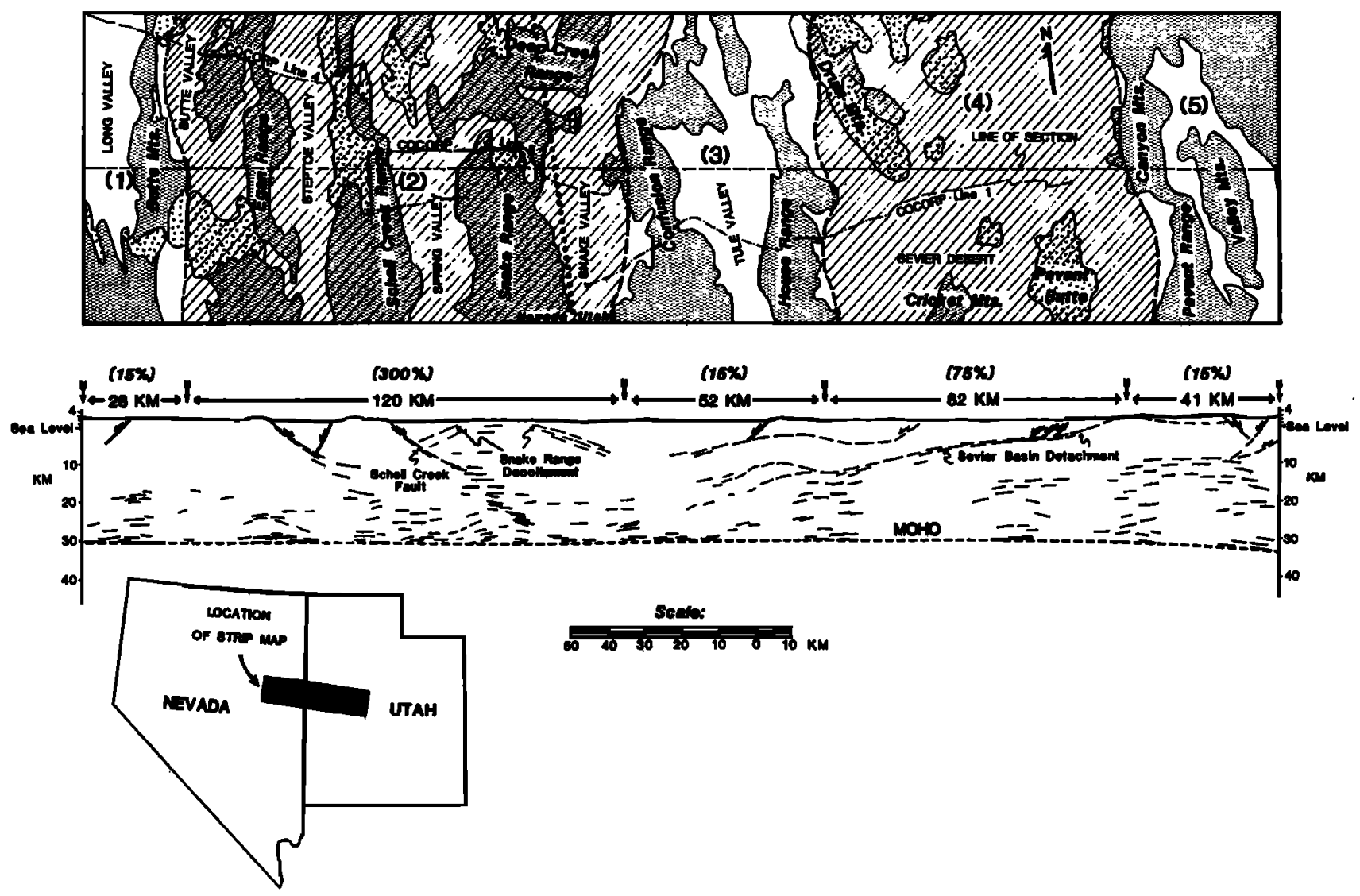

Figure 1. Geologic strip map and generalized cross-section across the eastern Great Basin, United States [from Gans, 1987]. Stippled areas represent Precambrian to Mesozoic carbonate and clastic rocks. Highly extended domains are highlighted with slanted lines. Note that the Moho is almost flat.

likely to have been added to the crust during extension, such additions will not have been localized enough, nor have had sufficient volume, to account for the lack of Moho topography. Thus lower crustal material must have flowed from regions where the amount of stretching is small to those where it is large [Gans, 1987].

Lower crustal flow is also required to account for structures seen on deep reflection profiles, especially those across the continental shelf around the United Kingdom [e.g., Brewer and Smythe, 1984; Kusznir and Matthews, 1988]. On almost all of these profiles the large normal faults that offset the layers of the upper crust do not cut the subhorizontal reflectors of the lower crust or the Moho, even though large planar structures that appear to be faults are not uncommon in the upper mantle. In these reflection profiles the faults in the upper crust often resemble tilted blocks or dominoes and are typically spaced $15-20 \mathrm{~km}$ apart. Flow on this length scale must occur at the base of the blocks and is, indeed, assumed to have done so by those who use simple models to model the vertical motions in such terrains [e.g., Jackson et al., 1988; Yielding, 1990]. This paper is primarily concerned with the nature of lower crustal flow over the $\sim 100 \mathrm{~km}$ length scale implied by
Figure 1 and with why, how, and when it occurs, rather than with the more localized flow that must occur at the base of tilted upper crustal blocks.

In section 2 we summarize previous models of lower crustal flow and then investigate the behavior of our own simple model, in which a fluid layer overlies a halfspace. We then discuss the conditions under which flow might be expected to occur in nature and identify the features of our model that are likely to be applicable. We then attempt to estimate the probable timescales, viscosities, and velocities that might be expected and discuss how our results may apply to geological problems.

\section{Model and Previous Work}

Authors in the past have studied lower crustal flow both analytically and numerically and have differed in their choice of rheology, boundary conditions, and number of layers. Kusznir and Matthews [1988], Gratton [1989], and Kruse et al. [1991] were interested in essentially the same problem that we address here, with Gratton's emphasis principally on the decay of crustal roots beneath mountains. Kusznir and Matthews [1988] 
realized the importance of crustal thickness in reducing the viscosity of the lower crust and obtained an expression for the timescale on which crustal thickness contrasts decay. Their expressions agree with ours when a printing error in their equation in Appendix 2 is corrected (N.J. Kusznir, personal communication, 1990). Kruse et al. [1991] and Kusznir and Matthews [1988] considered a power law rheology but did not allow the lower crustal channel walls to deform. $M^{c}$ Kenzie [1988] used the nonlinear solutions for channel flow obtained by Huppert [1982] to show that sharp topographic fronts could develop even when the rheology was viscous. Bird [1991] found the same behavior with a power law rheology, a result consistent with our findings (see below). More recently, both Nakada [1994] and Royden [1996] have investigated the effects of mantle flow on lower crustal deformation, whilst Hopper and Buck [1996] examined how a ductile lower crust influences rift morphologies. Zhong [1997] used a model similar to that analyzed below, but with a Maxwell rather than a simple viscous rheology, to argue that short-wavelength topography could remain uncompensated for extensive periods. Zhao and Morgan [1987] argued that the Indian crust is driving lower crustal thickening beneath Tibet. The deformation they studied by finite element methods is equivalent to one of the modes discussed below.

Rather than develop a complicated model which relies on the poorly known rheological properties of the lower crust, we use the simplest model that is likely to contain the important features that govern crustal flow (see Figure 2). It consists of a layer of fluid with density $\rho_{1}$ and viscosity $\eta_{1}$ overlying a fluid half-space of density $\rho_{2}\left(>\rho_{1}\right)$ and viscosity $\eta_{2}$. For the case of lower crustal flow, $\eta_{2}$ (representing the upper mantle) is probably much greater than $\eta_{1}$ (representing the lower crust), but as we shall see, we can use this model to investigate other situations as well. Under most conditions of fluid flow the velocity field does not correspond to either pure or simple shear, since both components of the velocity are nonzero, as is the vorticity, and both the velocity and the vorticity are functions of both $x$ and $z$. However, when the wavelength of the disturbance is large compared with the layer thickness, certain important flows occur which are good approximations to simple or pure shear.

Since both the upper and lower surface of the layer can independently move vertically, they are referred to as deformable boundaries. When they do so, the vertical fluid velocity at the boundary must equal the rate at which the boundary deforms. Other boundary conditions that must be satisfied are that the normal and tangential stress must be continuous and the vertical and horizontal velocities at the interface between the layer and the half-space must be the same. Though the shear stress must vanish on the upper surface of the layer, there is no restriction on the horizontal velocity. This boundary condition will be referred to as "free" or "stress free." It is also sometimes useful to impose

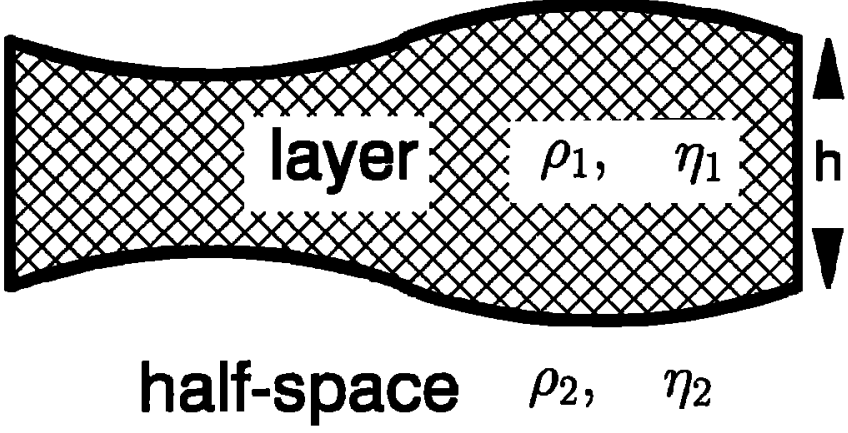

Figure 2. Cartoon to illustrate the model described in the text. A fluid layer of thickness $h$, viscosity $\eta_{1}$, and density $\rho_{1}$ overlies a fluid half-space with viscosity $\eta_{2}$ and density $\rho_{2}$.

another boundary condition on the upper or lower surface of the layer: that the horizontal velocity vanishes. Though this condition will be referred to as "rigid," it is a condition on the horizontal, not the vertical velocity. A boundary can be both rigid and deformable at the same time if it consists of a thin sheet of strong material separating the layer from the half-space. This would, for instance, be the appropriate boundary condition to use for a layer of fluid separated from a fluid half-space by a thin plastic film.

Below we argue that creeping flow only becomes important when the temperature (in $\mathrm{K}$ ) exceeds about 0.7 of the solidus temperature. Because the solidus temperature of the upper mantle is $\sim 1200^{\circ} \mathrm{C}$, it will only flow when the temperature exceeds $750^{\circ} \mathrm{C}$. Though this estimate is uncertain, the creep rate of the upper mantle is generally less than that of the lower crust when they are at the same temperature. Hence the Moho will act as a rigid boundary to lower crustal flow. The rigid layer beneath the Moho will, however, probably be no more than a few tens of kilometres thick in most places.

The other uncertainty that affects the calculations is whether lower crustal flow is Newtonian or involves power law creep. The transition between these regimes depends on both temperature and shear stress and is poorly constrained by existing laboratory experiments. However, the numerical experiments on power law creep carried out by Kruse et al. [1991] show that the use of a nonlinear stress-strain relationship rather than a Newtonian viscosity does not lead to qualitative differences in behavior. We therefore adopt a constant, Newtonian viscosity, since this greatly simplifies the calculations. Nor do we include the flexural rigidity of the upper crust, unlike Kaufman and Royden [1994]. In addition to calculating the velocity fields and response times of the model we also obtain the gravity field and its relation to the deformation of the upper surface.

We emphasize that our treatment assumes an instantaneous disturbance of the layer boundaries, the decay of which we then investigate as a function of wavelength, density contrast, and viscosity contrast. At least in 
some places, such as the Basin and Range province of the western United States, there is evidence that lower crustal flow occurred almost synchronously with regional extension. In the absence of such flow large variations in surface and Moho topography would have been produced if the upper and lower crusts had extended by the same amounts in the same place. We discuss this further in section 3.2 .

\subsection{Small Perturbations and Linear Behavior}

Because there are two surfaces involved in the model, there must be two response times that characterize the system. In general, both decay modes involve movement of both interfaces. When the deformations of the upper and lower surface of the layer are small compared with its thickness $h$, the equations governing the deformation are linear (see Appendix A). A number of asymptotic solutions to the equations, corresponding to limiting values of viscosity contrast or wavelength $\lambda$, can be obtained analytically, and we present the results as plots of response time $\tau$ against wavenumber $k$, where $k=2 \pi / \lambda$. All the calculations we show were carried out with $\rho_{1}=2.8 \mathrm{Mg} \mathrm{m}^{-3}$ and $\rho_{2}=3.3 \mathrm{Mg} \mathrm{m}^{-3}$. It is convenient to measure all lengths in terms of the layer thickness and all times in terms of a natural timescale $t_{0}$ of the model, where

$$
t_{0}=\eta_{1} / \rho_{1} g h,
$$

where $\eta_{1}$ and $\rho_{1}$ are the viscosity and density of the layer. Throughout the following, we neglect flow out of the plane.

2.1.1. A low-viscosity layer over a more viscous half-space. The simplest problem to solve is when the wavelength of the deformation is also small compared with $h$. The behavior of each surface is then independent, and the decay times for disturbances of wavelength $\lambda$ are easily found. The time $\tau_{a}$ required for a disturbance of the upper surface to decay to $1 / e$ of its initial size is then

$$
\tau_{a}^{\prime}=2 k^{\prime}
$$

or

$$
\tau_{a}=4 \pi \eta_{1} / \rho_{1} g \lambda,
$$

where $k^{\prime}=h k=2 \pi h / \lambda$ and the primes show that the variables have been scaled (Appendix $A$ ). The corresponding time $\tau_{b}$ for the lower boundary is

$$
\tau_{b}^{\prime}=\frac{2 k^{\prime}(r+1)}{(R-1)}
$$

or

$$
\tau_{b}=\frac{4 \pi\left(\eta_{1}+\eta_{2}\right)}{\left(\rho_{2}-\rho_{1}\right) g \lambda},
$$

where

$$
R=\rho_{2} / \rho_{1}, \quad r=\eta_{2} / \eta_{1} .
$$

Since $\rho_{1}>\left(\rho_{2}-\rho_{1}\right)$ and $\eta_{1}<\left(\eta_{1}+\eta_{2}\right)$, it follows that $\tau_{b}>\tau_{a}$. In other words, disturbances to the top sur- (a)

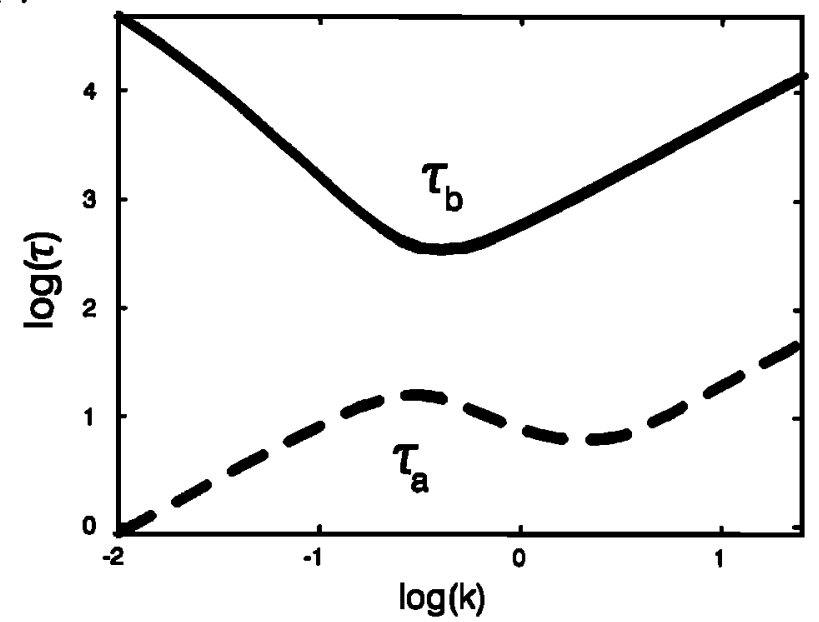

(b)

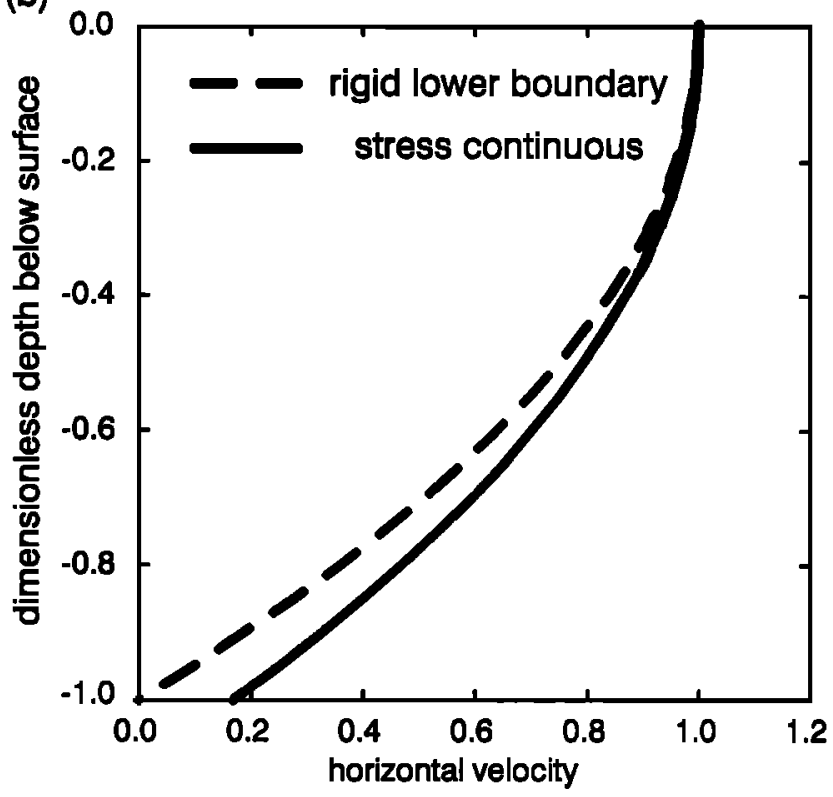

Figure 3. (a) Plot of response times $\tau^{\prime}$ versus wavenumber $k^{\prime}$ for a density contrast $R=1.18$ and viscosity contrast $r=\eta_{2} / \eta_{1}=50$. (b) Plot of velocity versus depth within the layer for the same density and viscosity contrasts as in Figure 3a, when $k^{\prime}=0.1$. Depth and velocity are normalized to the thickness of the layer. The solid curve is the velocity when the lower boundary of the channel is that the stress and velocity are continuous between the layer and the half-space, and the dashed curve is the velocity when the lower boundary is rigid and deformable.

face decay faster than those on the interface between the half-space and the layer because the density contrast across the top surface is greater. If $\rho_{2}=\rho_{1}$, the only force driving the flow is the deformation of the upper surface. The time $\tau_{a}$ therefore corresponds to the isostatic response time of the system to surface loads.

The analytic solutions given in (3) and (5) are only valid when $h \gg \lambda$. The more general variation of response times with wavenumber is shown in Figure 3a, which contains a plot of $\log \tau_{a}^{\prime}$ and $\log \tau_{b}^{\prime}$ as functions of 

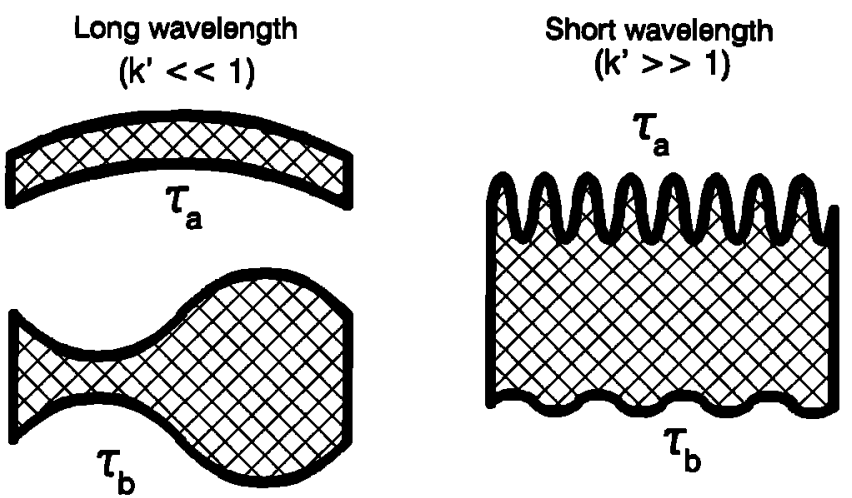

Figure 4. Sketches of the deformation associated with the two response times of the system in Figure 2 at very long and very short wavelengths.

$\log k^{\prime}$ for $\eta_{2} / \eta_{1}=50$ when the shear stress is continuous on the lower interface of the layer. The types of deformation associated with the two response times at large and small wavelength are illustrated in the cartoons in Figure 4. When $k^{\prime} \gg 1$ (Figure 4, right), both response times are proportional to $k^{\prime}$. When $k^{\prime} \ll 1$ (Figure 4, left), $\tau_{a}^{\prime}$ is again proportional to $k^{\prime}$, and both the upper and lower boundaries of the layer deform at the same velocity. The corresponding flow is that of the isostatic response of a half-space with viscosity $\eta_{2}$. The response time is controlled by flow within the half-space, and the only flow that occurs within the layer is that associated with bending. The flow associated with the other response time $\tau_{b}^{\prime}$ is of more geological interest. It corresponds to the decay of compensated crustal thickness variations by the lateral flow of the crust.

The horizontal velocity profile in Figure 3b shows that the flow is concentrated in the layer. Because the viscosity of the half-space is so much greater than that of the layer, the velocity at the interface is small and the flow is similar to that with a rigid deformable lower boundary, shown with a dashed line in Figure 3b. It is this mode that Zhao and Morgan [1987] analyzed by finite element methods in their study of Tibetan deformation. Since $k^{\prime} \ll 1$, the wavelength of the crustal thickness variations is large compared with the layer thickness and the horizontal velocity is large compared with the vertical. Hence the deformation within the layer is principally by simple shear, with only a small component of pure shear, and the viscous resistance is large. If the amplitude of the deformation is kept constant as $k^{\prime}$ decreases, the gravitational force driving the flow also remains constant, but the distance that the material in the layer must be transported increases as the wavelength of the disturbance increases. It is for this reason that $\tau_{b}^{\prime}$ increases so rapidly as the wavelength increases. The asymptotic analysis has not been done for this case, but Figure 3a suggests that $\tau_{b}^{\prime} \propto k^{\prime-2}$ when $k^{\prime} \ll 1$ and $\eta_{2} \gg \eta_{1}$. As Figure 3 shows, $\tau_{b}^{\prime}\left(k^{\prime}\right)$ has a minimum value when $k^{\prime} \simeq 0.3$ or $\lambda \simeq 20 h$ : thus, if $h \simeq 10 \mathrm{~km}$, then $\lambda \simeq 200 \mathrm{~km}$. Longer- and shorterwavelength disturbances will decay more slowly. The dimensionless wavenumber for the most rapidly decaying disturbance is not very different from that of 1.05 which Smith [1975] found for the most rapidly growing disturbance when a Newtonian layer is strained by pure shear. This value increases to $1.57-1.85$ when the material is non-Newtonian [Smith, 1975]. In detail, however, Smith's problem is rather different from that considered here because gravity is absent and the instability is driven by a large-scale viscous flow which is not present in our model.

The flow associated with the response time $\tau_{b}^{\prime}$ must be responsible for removing the crustal thickness variations generated by the differential stretching in Figure 1. The position and shape of the minimum in $\tau_{b}^{\prime}\left(k^{\prime}\right)$, and the values of $\tau_{b}^{\prime}$ and $k^{\prime}$ at that minimum, depend on the density and viscosity contrasts, as will be seen in Figures 5 and 6 . The important result is that there is a minimum in $\tau_{b}^{\prime}\left(k^{\prime}\right)$ and that it occurs where the wavelength is a few times the layer thickness $\left(\lambda=2 \pi h / k^{\prime}\right)$. Nakada [1994] found a similar result, although he does not show an increase in $\tau_{b}^{\prime}$ at short wavelengths.

When the viscosity of the layer and the half-space are the same but their densities are different (Figure 5), the behavior of $\tau_{a}^{\prime}$ becomes simple. However, $\tau_{b}^{\prime}$ still has a minimum because the flow required to remove longwavelength variations is restricted to the layer. The minimum in $\tau_{b}^{\prime}\left(k^{\prime}\right)$ is rather shallower than in Figure $3 a$ and has shifted position, to a smaller value of $\tau_{b}^{\prime}$, and a larger value of $k^{\prime}$. Note that $\tau_{a}^{\prime}$ is always less than $\tau_{b}^{\prime}$ for a given value of $k^{\prime}$ in both Figures 3 and 5 . At long wavelengths (i.e., $k^{\prime} \ll 1$ ), isostatic compensation is always attained more quickly than the decay of crustal thickness contrasts.

2.1.2. A viscous layer over an inviscid fluid. A very different type of behavior occurs when $\eta_{1} \gg$

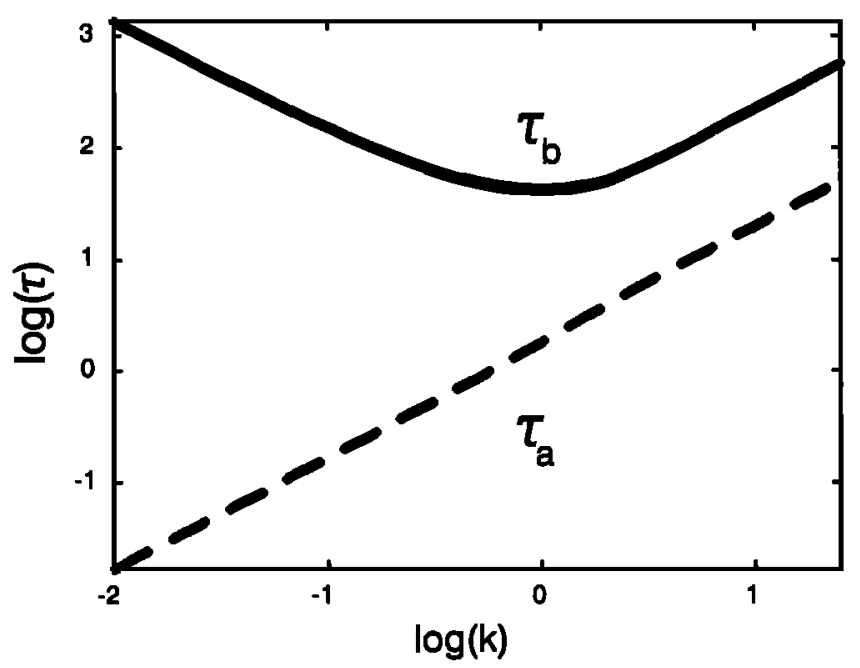

Figure 5. Plot of response times versus wavenumber, as in Figure 3a, but in this case with no viscosity contrast $\left(r=\eta_{2} / \eta_{1}=1\right)$. 
$\eta_{2}$. This problem is closely related to that studied by Solomon et al. [1982], who used a viscous layer overlying an inviscid half-space of different density to study the recovery of impact basins. Figure $6 \mathrm{a}$ shows the behavior of $\tau_{a}^{\prime}\left(k^{\prime}\right)$ and $\tau_{b}^{\prime}\left(k^{\prime}\right)$ when $\eta_{2} / \eta_{1}=0.004$, and analytic expressions for $r=0, k^{\prime} \ll 1$ are obtained in Appendix A. The numbers in Figure 6a against the segments of the curves show the value of $n$ where

$$
\tau^{\prime} \propto k^{\prime n} \text {. }
$$

(a)

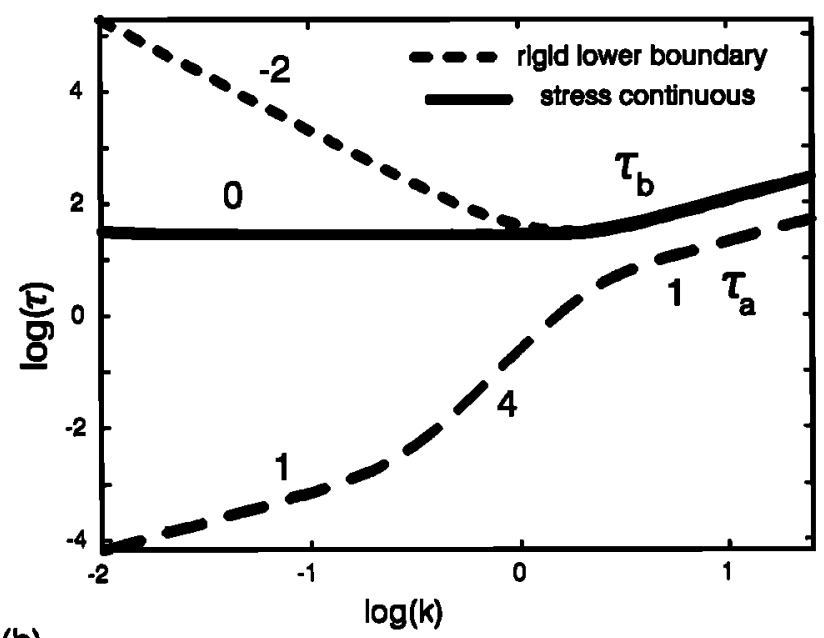

(b)

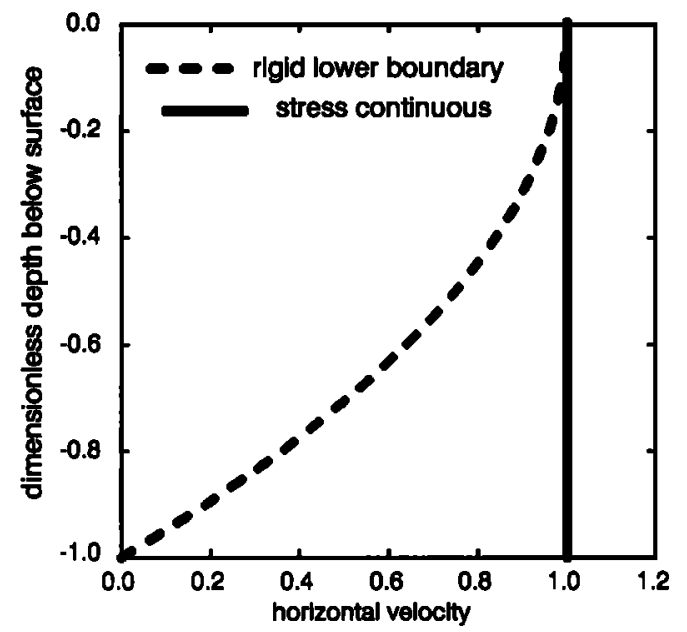

(c)

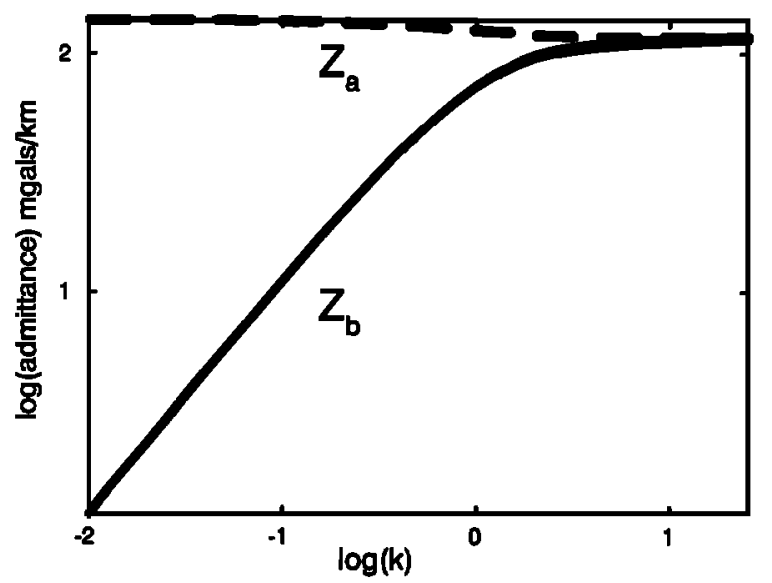

When $k^{\prime} \gg 1, \lambda \ll h$, and the upper and lower boundaries of the layer move independently. The behavior of $\tau_{a}^{\prime}$ when $k^{\prime} \ll 1$ is also the same as before and corresponds to isostatic recovery with a time constant controlled by the properties of the half-space. The behavior of $\tau_{b}^{\prime}$ as $k^{\prime} \rightarrow 0$ is, however, quite different from that in Figures 3 and 5 because the crustal thickness can change by deforming the layer by pure shear. The velocity profile is illustrated in Figure $6 \mathrm{~b}$ as the solid line and shows that the velocity gradients within the layer are negligible. That the stress free boundary condition on the lower boundary of the layer is indeed responsible for this behavior is shown by calculating $\tau_{b}^{\prime}$ with a rigid instead of a free boundary, shown by the line with short dashes in Figures $6 \mathrm{a}$ and $6 \mathrm{~b}$. The time $\tau_{b}^{\prime}$ is then proportional to $k^{\prime-2}$, as the asymptotic analysis in Appendix A (equation (A23)) also shows. Thus viscous dissipation rate is much smaller and the relaxation time much faster when the layer deforms by pure shear, rather than by simple shear. This result is also clear from Figure 6a, which shows that, for a value of $k^{\prime}=10^{-2}, \tau_{b}^{\prime} \sim 10^{5}$ for simple shear (dashed curve) but $\tau_{b}^{\prime} \sim 10^{1.5}$ for pure shear (solid curve).

Because $\tau_{b}^{\prime}$ is constant when $k^{\prime} \ll 1$ and the lower boundary is free, all perturbations decay at the same rate. Therefore the shape of the deformation does not change. England and $M^{c}$ Kenzie [1982] found the same behavior for a deforming thin sheet with Newtonian viscosity, where both upper and lower boundaries were free, and were for this reason unable to produce steep surface gradients. A non-Newtonian rheology, however, did produce such gradients. Therefore whether the flow is Newtonian or non-Newtonian has an important in-

Figure 6. (a) Plot of response times versus wavenumber, as in Figure 3a, but with the viscosity contrast $r=\eta_{2} / \eta_{1}=0.004$. The behavior is similar to that of a viscous layer overlying an inviscid fluid. Two curves are shown for $\tau_{b}^{\prime}$ : the solid curve shows the behavior when the stress is continuous on the lower boundary of the layer and corresponds to the conditions used in thin sheet analysis of lithosphere deformation [e.g., England and $M^{c}$ Kenzie, 1982]; the dashed curve is for a rigid and deformable lower boundary to the layer. The numbers adjacent to the curves are the slopes in log-log space (see equation (7)). (b) Plot of velocity versus depth within the layer for the same density and viscosity contrasts as in Figure 6a, when $k^{\prime}=0.01$. Depth and velocity are normalized to the thickness of the layer. The solid curve is the velocity when the lower boundary condition on the channel is that the stress and velocity are continuous between the layer and the half-space (the thin sheet approximation), and the dashed curve is the velocity when the lower boundary is rigid and deformable. (c) Plot of admittance $Z$ versus wavenumber for the viscosity and density contrasts for the continuous stress curves in Figure 6a. The curve $Z_{a}$ corresponds to the deformation associated with response time $\tau_{a}^{\prime}$, and $Z_{b}$ with $\tau_{b}^{\prime}$. 
fluence on the solution in this limiting case. The same does not appear to be true for channel flow in the lower crust [Gratton, 1989; Kruse et al., 1991]; we demonstrate later that for larger perturbations even Newtonian fluids can develop steep surface gradients.

The complicated behavior of $\tau_{a}^{\prime}$ between $k^{\prime}=1$ and $k^{\prime}=0.1$ can also be understood with the help of the asymptotic expressions in Appendix A. When the viscosity of the half-space is zero, the isostatic response is controlled by the viscosity of the layer and the time constant is proportional to $k^{\prime 4}$ (equations (A20) and (A22)). This behavior is clearly shown in Figure 6a. However, as the wavelength increases, the resistance of the layer to deformation rapidly becomes unimportant, and the isostatic response is governed by the properties of the half-space.

The behavior of the ratio of the gravity anomaly to the surface deformation, known as the admittance, $Z$, as a function of $k^{\prime}$ for the two modes of decay is illustrated in Figure 6c. The isostatic response shows a large admittance $Z_{a}$ (dashed curve) that varies little with wavelength. Hence there is a large amount of gravitational potential energy associated with this deformation that is available to drive the flow. As would be expected, the gravity anomaly associated with crustal flow is small (solid curve) because the crust is isostatically compensated. Hence the small value of $Z_{b}$ calculated for $\tau_{b}^{\prime}$ agrees with the absence of large gravity anomalies associated with long-wavelength compensated variations in crustal thickness. This behavior is unlike that found by Zhong [1997], whose Maxwell rheological model contains some modes with long time constants that also have large values of $Z$. This difference suggests that it is the elastic forces in his model that cause this difference.

\subsection{Larger Perturbations: Nonlinear Behavior and Channel Flow}

The discussion above is entirely concerned with the behavior of perturbations to the surface or the interface the amplitude $a$ of which is small compared with $h$. Though the value of $a / h$ at which the approximation ceases to be useful cannot be estimated without numerical experiments, it is only likely to be accurate if $a / h<0.1$. If this condition is not satisfied, the flow depends nonlinearly on the amplitude of the disturbance and numerical techniques are generally required to solve the flow problem. However, as Huppert [1982] showed, progress can still be made analytically if certain conditions are satisfied. He discussed the problem of magma spreading over a rigid undeformable surface and obtained a similarity solution that was valid when the horizontal extent of the magma was large compared with its thickness. Because the shape of the layer is given by a similarity solution, it does not change with time if the $x$ axis is suitably scaled (see equations (B13) and (B14)). It is straightforward to show that a layer of fluid spreading over a rigid but deformable surface satisfies the same equation that Huppert [1982] solved (Appendix B). Furthermore, only the numerical constant changes if a rigid but deformable boundary condition is imposed on the lower surface of the layer. It is the rigidity rather than the deformability that controls the behavior. As long as at least one boundary is rigid (i.e., the horizontal velocity component at the boundary is zero), the deformation of the layer will be by simple shear and a flow front will develop. Whether or not the boundaries are deformable changes the numerical factors but not the exponent of $k^{\prime}$. Furthermore, if the viscosity of the lower crust is much less than that of the upper mantle, the style of flow in the lower crust is little affected by extension of the upper mantle (Figure $3 \mathrm{~b}$ ). Similarly, it makes little difference whether it is the upper mantle or the upper crust (or both) that is rigid, since the rigidity of either boundary will force channel flow to occur. If, however, both upper and lower boundaries are stress free, Huppert's analysis does not apply because pure shear deformation is then allowed, and the form of the solutions is completely changed.

Huppert [1982] also remarks that almost all initial shapes will approach the similarity solution with increasing time. Figure 7 shows the evolution of three different initial liquid shapes, obtained by solving Huppert's equation 2.9 with an implicit finite difference scheme. The thin line is the shape predicted by the similarity solution, and the dotted line is an initially triangular distribution having the same total area. Although this latter shape does not possess a sharp front initially, it approaches the similarity solution over time. The bold line is the evolution of a shape with a smaller initial lateral thickness contrast and shows that a large contrast is required to cause the sharp fronts to develop.

The linear theory in Appendix A gives some indication of how such fronts arise when one or both boundaries are rigid. Under these circumstances (A23) shows that $\tau_{b} \propto h^{-3}$. Hence disturbances with a particular wavelength decay very much faster on a thick layer than on a thin one. This effect allows the liquid in Figure 7 to flow rapidly toward the front, even though the slopes of the upper and lower interfaces are small. Only as it approaches the front does its velocity decrease, causing the liquid to pile up and in this way maintain the front. It is also important that the shape is independent of the viscosity of the spreading layer: only the rate of evolution of the shape is controlled by the viscosity.

\subsection{Summary}

This discussion shows that many important features of the response of the crust and upper mantle to variations in crustal thickness can be understood using simple analytical expressions. An important result is that variations in lower crustal thickness whose wavelength is a few times the thickness of the layer will decay the most 


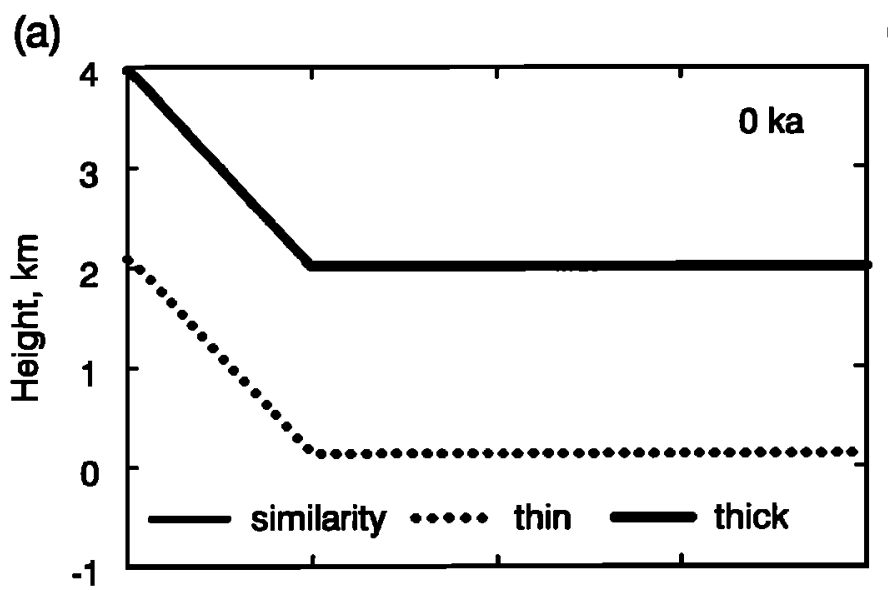

(b)
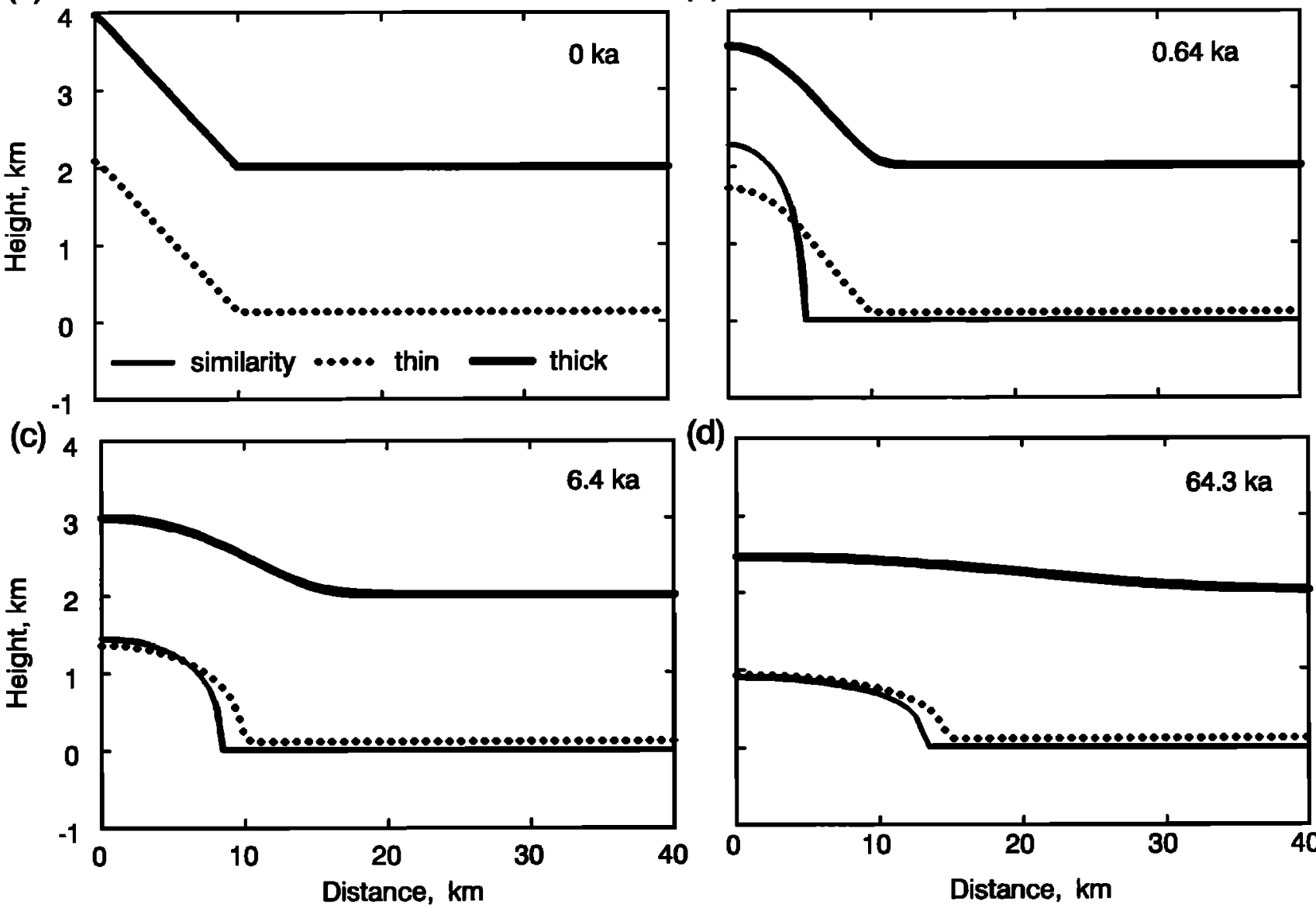

(d)

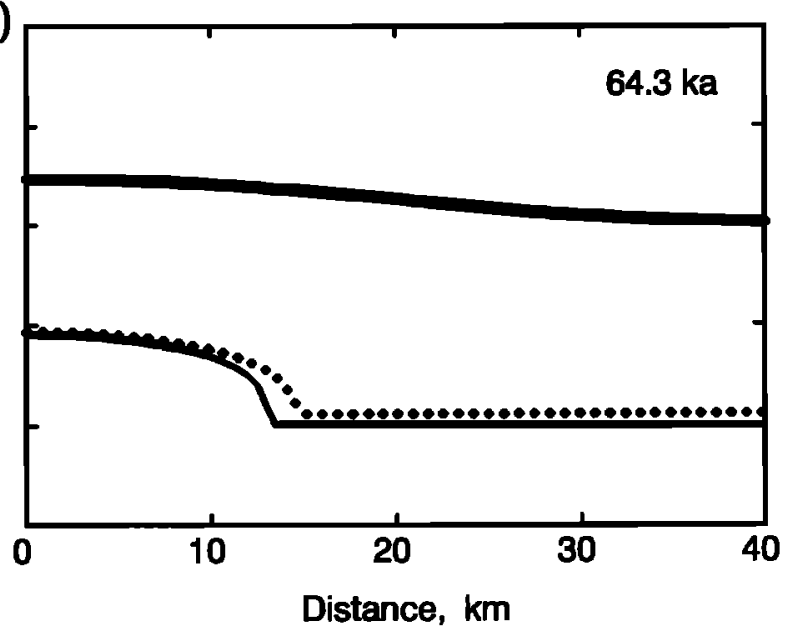

Figure 7. (a) Initial topographic profiles for two models. In all cases the kinematic viscosity $\nu$ is $10^{14} \mathrm{~m}^{2} \mathrm{~s}^{-1}$ and the acceleration due to gravity $g$ is $10 \mathrm{~m} \mathrm{~s}^{-2}$. The bold line is a triangular profile superimposed on a layer of thickness of $2 \mathrm{~km}$, and the dotted line is a profile imposed on a layer whose thickness is $100 \mathrm{~m}$. The fine lines in Figures $7 \mathrm{~b}-7 \mathrm{~d}$ show the similarity solution from Huppert's [1982] equation 2.12 having the same total area as the triangular profile. The evolution of initially triangular profiles is calculated from implicit finite difference solution to Huppert's [1982] equation 2.9, and the similarity solution profile is given by his equation 2.12 . Shape of fluids (b) after 640 years, (c) after $6.4 \times 10^{3}$ years, and (d) after $64.3 \times 10^{3}$ years. Note that a sharp step has developed only for the dotted line, which closely resembles the similarity solution. A large thickness contrast is needed for this effect to occur.

rapidly. This wavelength dependence was also noticed by Kusznir and Matthews [1988], Kruse et al. [1991], and Nakada [1994]. We found that the decay in crustal thickness contrasts occurs more slowly than the attainment of isostatic equilibrium. This result is likely to be general.

Another important result is that any local region of low-viscosity, lower crustal material at the base of thick crust will spread outward. If there are large lateral variations in the thickness of this low-viscosity region and if it is bounded either above or below (or both) by highviscosity material, the fluid will develop a sharp front as it flows.

\section{Geological Consequences of Flow in the Lower Crust}

In this section we examine some of the consequences of lower crustal flow and their significance for various geological problems. It is not our intention to use the simplified and idealized treatment of flow in section 2 to attempt a detailed explanation of the geology in particular localities but rather to point out how lower crustal flow might influence the development and geometry of some geological phenomena.

It is generally accepted that the viscosity of the lower crust is lower than that of both the mantle and the up- 
per crust [Meissner and Kusznir, 1987; Strehlau and Meissner, 1987], and therefore $r>1$. When the lower crust flows so as to equalize crustal thickness, the relevant problem is channel flow with a rigid deformable surface below and either a rigid or free deformable surface above. The flow is likely to be principally by simple shear, and Huppert's [1982] equations apply. The channel that flows in the lower crust is unlikely to exceed $\sim 30 \mathrm{~km}$ in thickness, and deforms so as to smooth Moho topography on a scale of 100-200 km (Figure 1), so that $k^{\prime} \leq 1$ for the problems of interest here. The two response times that concern us are likely to behave in a similar way to those in Figure 3a when $k^{\prime} \leq 1$. The time $\tau_{a}^{\prime}$ is then always much smaller than $\tau_{b}^{\prime}$, so isostatic equilibrium is quickly established, and the negative slope of $d \tau_{b}^{\prime} / d k^{\prime}$ at longer wavelengths will lead to the development of fronts. Notice that this is true because $\eta_{1} \ll \eta_{2}$. The actual value of the mantle viscosity is unimportant.

\subsection{What Determines Whether Flow Occurs?}

Lower crustal flow is expected to occur even when the upper mantle and crust can deform by brittle failure. Creeping flow at geologically important rates can occur when the absolute temperature of a solid exceeds about $0.7 T_{s}$, where $T_{s}$ is the solidus temperature in $\mathrm{K}$ [Stocker and Ashby [1973]. The solidus temperature of the lower crust is $700^{\circ}-900^{\circ} \mathrm{C}$, so flow should occur where the temperature exceeds $400^{\circ}-500^{\circ} \mathrm{C}$. Hence, if the crustal thickness is $30 \mathrm{~km}$ and the temperature gradient is $20^{\circ} \mathrm{C} \mathrm{km}^{-1}$, the bottom $5-10 \mathrm{~km}$ of the crust will be able to flow. These temperature estimates are considerably lower than those of Kruse et al. [1991], who use values of the activation energy for creep determined in the laboratory to estimate that lower crustal flow will only occur over geological timescales when the temperature exceeds $700^{\circ}-1000^{\circ} \mathrm{C}$. Both temperature estimates are less than the temperature of basaltic magma, which is likely to be one of the main causes of increases in lower crustal temperature that lead to flow (see below).

As we showed above, provided the upper mantle does not flow horizontally in response to lower crustal flow, the behavior of the upper crust has a minor influence (compare equations (B9) and (B11)). These arguments show that the lower crustal flow is only likely to occur where the crustal thickness exceeds 20 or $25 \mathrm{~km}$ [see also Kusznir and Matthews, 1988]. Hence it should largely be restricted to continents, though it may also be important in oceanic regions such as Iceland, where the crust is thick and the heat flow is high.

Any contrast in crustal thickness generates buoyancy forces that act so as to try and make the crustal thickness uniform. However, these forces are not always successful in removing thickness contrasts, and there are many places on the continents where Moho topogra-
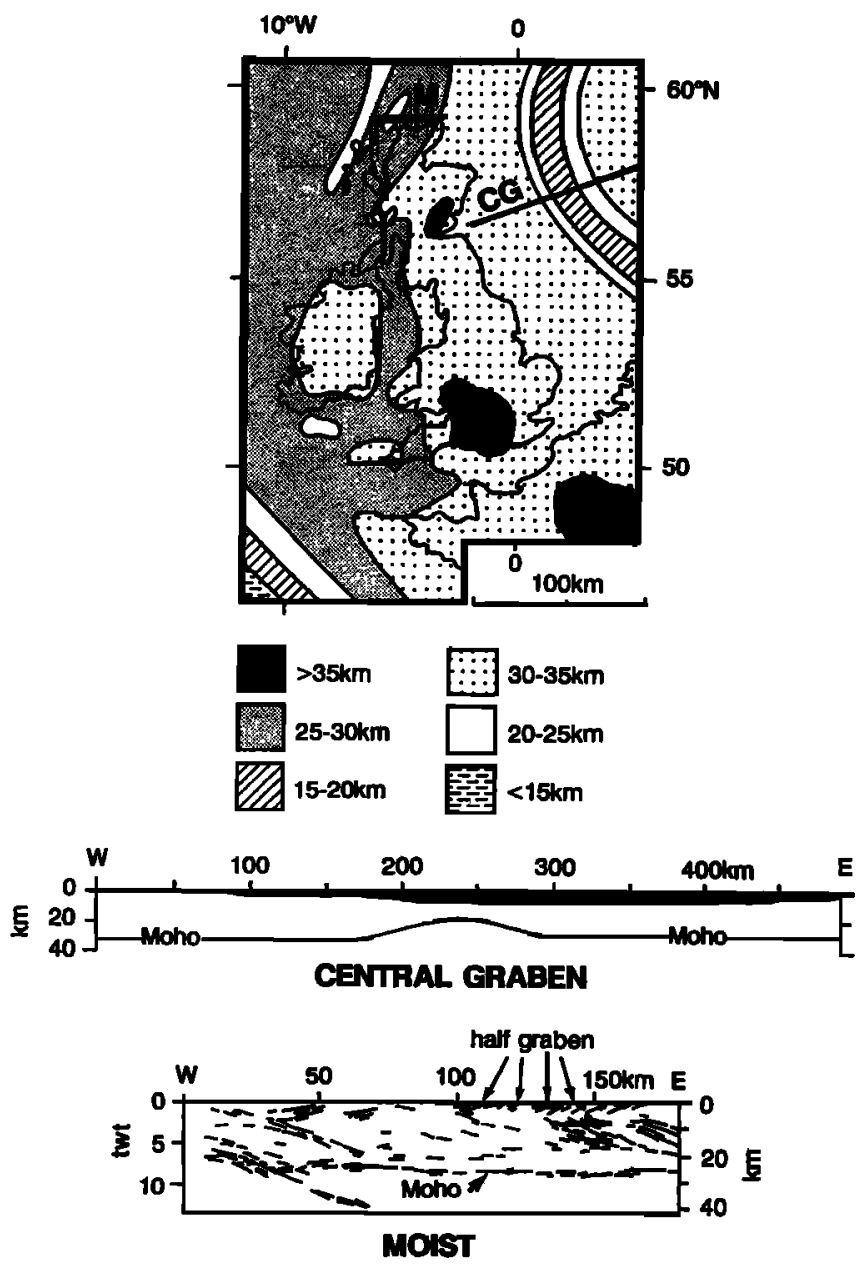

Figure 8. Map of estimated Moho depth around the British Isles [after Meissner et al., 1986] and cross sections to show the refraction profile of Barton and Wood [1984] across the Central Graben of the North Sea [adapted from Barton and Wood, 1984], and along the lines of the MOIST seismic reflection profile north of Scotland [adapted from Brewer and Smythe, 1984]. The Central Graben section is along the line CG on the map and is shown with sedimentary cover as solid area. The MOIST section is a migrated line drawing along the line marked $M$ on the map.

phy has been preserved for many millions of years. The Alps and Appalachians still have deep roots and depressed Mohos [e.g., Bois and ECORS, 1990; James et al., 1968]; the northern and central North Sea (Figure 8) and the Aegean Sea, both extensional provinces, still have elevated Mohos [Barton and Wood, 1984; Holliger and Klemperer, 1989; Makris and Stobbe, 1984]. Even among rifted continental margins, where the difference between oceanic and continental crustal thickness might be expected to produce substantial buoyancy forces [e.g., Bott and Dean, 1972], there are some, such as the Armorican-Biscay margin, that show a steady de- 
crease in the thickness of continental crust toward the ocean over a distance of 100-200 km [e.g., Ginzburg et al., 1985]. Therefore there are places where the strength of either the lower crust or the uppermost mantle is sufficient to resist the buoyancy forces and maintain a longwavelength topography on the Moho. However, in all these examples, there is no sign of shorter-wavelength Moho topography mimicking the sawtooth topography of tilted blocks in the upper crust, and so some flow has occurred, at least at these shorter wavelengths.

Elsewhere, there are places where a strong case may be made that flow in the lower crust has reduced or removed long-wavelength topography on the Moho. Several authors have suggested this effect in parts of the Basin and Range province of the western United States [e.g., Gans, 1987; Block and Royden, 1990; Kruse et al., 1991; Bird, 1991]. The interior of the Tibetan Plateau is also extremely flat, suggesting that flow may have occurred over hundreds of kilometers [Fielding et al., 1994]

Lower crustal flow is also likely to have occurred immediately north of Scotland, where deep seismic reflection profiles show fault-bounded half graben, that must represent a significant amount of upper crustal extension, almost at the sea bed (Figure 8) [e.g., Brewer and Smythe, 1984]. There is, however, no evidence of postrift thermal subsidence, and differences in the Moho depth beneath this region and beneath the adjacent Scottish mainland, which has undergone insignificant stretching in the upper crust [e.g., Meissner et al., 1986], are small. These observations suggest that the lower crust may have flowed from under Scotland toward the offshore region [see also Kusznir and Matthews, 1988]. Alternatively, the rifting may have been accompanied by magmatism [White and Lovell, 1997] which reduced the difference in crustal thickness.

In these examples, there are some obvious patterns. The lower crust has flowed during extension in places where earlier shortening had probably thickened the crust to $\sim 40 \mathrm{~km}$, such as in the Basin and Range province [Coney and Harms, 1984] and in Scotland [Watson, 1984; McClay et al., 1986]. In contrast, the best examples of extension creating significant variations in crustal thickness over relatively short distances are places, such as the Salton Trough in California [Fuis et al., 1984] or the North Sea [Barton and Wood, 1984], where either the crust was never thick, or earlier extension and/or erosion had already uniformly thinned it to $\leq \sim 30 \mathrm{~km}$. These observations suggest that only crust thicker than $\sim 30 \mathrm{~km}$ has a weak lower crustal channel that is thick enough for flow to occur over long distances in a reasonable geological time and in this way to remove Moho topography. We would clearly expect this relationship from the behavior shown in
Figure 3a, which shows the wavelength that relaxes fastest. If the channel is thin, this wavelength will be relatively short $\left(k^{\prime} \propto h / \lambda\right)$ : perhaps enough to smooth the Moho beneath tilted blocks in the upper crust, but insufficient to smooth the longer-wavelength variations in crustal thickness between stretched and unstretched upper crustal terrains. As the channel thickness increases, the time required for this longer-wavelength flow will decrease dramatically. In particular, overthickened crust that is heated, for example, by basaltic underplating, could have a low-viscosity crustal channel that is thick enough to flow easily and to compensate for upper crustal strain variations on a very short timescale.

The association of lower crustal flow with magmatism is particularly striking in the Basin and Range province. Gans [1987] and Gans et al. [1989] pointed out the close association in space and time of extensional faulting and volcanism in many parts of the Basin and Range and argued that the influx of mantle derived basalt may have weakened the crust sufficiently to cause it to collapse. In particular, the areas where the upper crust has extended the most and where lateral flow of lower crustal material from beneath adjacent less extended upper crustal areas must have occurred (Figure 1) are all areas of voluminous volcanism immediately prior to and synchronous with the extension. This magmatic activity may have reduced the lower crustal viscosity by introducing heat (see section 3.2). The association of lower crustal flow with igneous activity is not surprising. Whether, and how much, basaltic magma is generated by adiabatic decompression during extension depends on the amount of stretching, the potential temperature of the asthenosphere, and the initial thickness of the lithosphere [ $M^{c}$ Kenzie and Bickle, 1988]. Most intracontinental sedimentary basins have stretched less than a factor $(\beta)$ of two and will not have generated sufficient volumes of partial melt to affect the total crustal thickness. Where asthenosphere temperatures are elevated or where extension factors are extreme, it is easy to generate a few kilometers of partial melt, which, as we demonstrate below (section 3.2), is sufficient to reduce the viscosity of the lower crust enough to cause flow. Thus there are circumstances in which we might expect igneous activity to accompany extension, though the adiabatic decompression resulting from the extension may not be the mechanism by which the magmas are produced. In the Basin and Range in particular, the onset of magmatic activity appears to predate extension at the surface [Gans et al., 1989].

We conclude that both initial crustal thickness and the presence of magmatic activity play an important role in encouraging long-wavelength flow in the lower crust. There are places where the crust was thick prior to extension and yet Moho topography remains. One 
example is the northern Aegean Sea, where deep offshore basins that are bounded by large normal faults that have elevated the Moho beneath them [Makris and Stobbe, 1984; Mercier et al., 1989; Taymaz et al., 1991]. Most of this extension probably occurred in the last $5 \mathrm{Myr}$ and was accompanied by only minor igneous activity [Bellon et al., 1979]. Another example is the Caledonian-Appalachian orogen. The Appalachians have a crustal root [James et al., 1968] that did not flow away as a result of the adjacent extension when the Atlantic Ocean opened. Yet the Scottish part of the same orogen no longer has a Moho significantly deeper than its adjacent stretched offshore region. It may be significant that the Scottish part alone was affected by the Tertiary igneous activity that accompanied the opening of the North Atlantic (see section 3.2). At the other extreme, there are places where extension accompanied by igneous activity has nonetheless produced an elevated Moho. An example is the Salton Sea region in California [Fuis et al., 1984], though here the crust had not been thickened prior to extension.

\subsection{Scale and Timing of Flow}

An important result of the analysis in section 2 is that the relaxation of crustal thickness contrasts occurs on a timescale that is very wavelength dependent. The lengthscale that relaxes fastest corresponds to $\sim 10$ times the thickness of the flowing layer, or in the region of $100-200 \mathrm{~km}$ for a channel 10-20 km thick. Substantially longer and shorter wavelengths relax much more slowly (Figure 3a). This effect depends on the shape of the minimum in $\tau_{b}^{\prime}\left(k^{\prime}\right)$ and hence on the viscosity contrast, which is not well known in nature. Thus the minimum in $\tau_{b}^{\prime}$ occurs at $\lambda \simeq 20 h$ (Figure 3a) for a viscosity contrast of $r=50$. If, however, $r=10$, the minimum in $\tau_{b}^{\prime}$ occurs at $\lambda \simeq 10 h$. If heat from igneous intrusions is important in lowering the lower crustal viscosity, only those wavelengths whose time constant is shorter than the thermal time constant will be able to relax. We should therefore look for geological evidence of flow on the scale of $\sim 100-200 \mathrm{~km}$. This is the scale on which flow has occurred in Figure 1.

The geological and thermal history of an extended region is greatly influenced by whether the lower crustal flow was contemporary with, or later than, the extension. If we take the minimum value of $\tau_{b}^{\prime}=316$ from Figure $3 \mathrm{a}$, and a value of $\eta_{1} / \rho_{1}=10^{17} \mathrm{~m}^{2} \mathrm{~s}^{-1}$, then equation (A14) gives a minimum response time $\tau_{b}$ of 7 Myr for a lower crustal layer $15 \mathrm{~km}$ thick. This estimate is proportional to the viscosity, which is uncertain by at least an order of magnitude, and also depends on the viscosity contrast, $r$. Thus if $r=10$, the minimum response time $\tau_{b}$ is only $3 \mathrm{Myr}$. Nonetheless, these calculations indicate that the response time can be short, of the order of 1-10 Myr, and that significant flow can begin during the extension. If it does, then there may never be much difference in elevation between relatively stretched and unstretched areas of the upper crust, nor much topography on the Moho, though presumably some would have been necessary to drive the flow.

In the Basin and Range province, upper crustal extension and magmatism are synchronous [Gans, 1987, Gans et al., 1989], and there is evidence that lower crustal flow was also synchronous with the extension. Had the flow not occurred during extension, the highly extended corridors of upper crust, where $\beta>2$, would have been topographic depressions $1-3 \mathrm{~km}$ deep and would have thick accumulations of sedimentary and volcanic rocks. Although thick sections of such rocks are preserved locally within the half graben of the extended corridors, there is no evidence that the corridors themselves were regional depocenters. The most compelling evidence that they were not comes from the distribution of regionally extensive ignimbrite sheets. Both the Kalamazoo Tuff in east central Nevada [Gans et al., 1989] and the Peach Springs Tuff along the Colorado River extensional corridor [Young and Brennan, 1974] were erupted within or adjacent to areas that were undergoing localized large magnitude extension at the time they were erupted. These ignimbrites formed thin, regionally extensive sheets and were deposited on both highly extended and little extended ground. For example, the Kalamazoo Tuff, which was erupted from near the center of the extensional corridor in the eastern part of central Nevada, is found as far east as the Confusion Range and as far west as the Butte Mountains (see Figure 1 and Gans et al. [1989]), both of which have undergone little extension. Similarly, the Peach Springs Tuff is found from the central Mojave Desert to the Colorado Plateau transition zone [Glazner et al., 1986] and crosses several domains of highly extended and relatively unextended upper crust. These sheets were emplaced by flow over the ground surface and are typically only tens of meters thick. They are not significantly thicker within the extensional corridors than outside. As ignimbrites typically pond within topographic depressions, there cannot have been any large long-wavelength elevation differences between extended and unextended areas. Extension at the latitude of the Whipple Mountains occurred principally between 20 and $17 \mathrm{Ma}$ [Davis, 1988; Nielson and Beratan, 1990], so for the 18.5 Ma Peach Springs Tuff [Nielson et al., 1990] to have flowed across a region with little variation in elevation, lower crustal flow must have occurred on a timescale of $\sim 1 \mathrm{Myr}$. This is consistent with our assertion that significant relaxation of long-wavelength topographic and Moho elevation contrasts can occur within a time scale of only a few million years. 
If flow were to occur long after extension and the associated thermal subsidence had ceased, it would produce uplift of the synrift and postrift sediments. Such uplift may raise the sediments above sea level, where they could be eroded. Kaufman and Royden [1994] have suggested that postrift uplift observed in the Halloran Hills area in eastern California is due to later lower crustal flow.

Another way in which postextensional flow might be recognized is by hydrocarbon source rocks that are too mature for their present depth of burial. Postextensional flow provides a mechanism for structural inversion that does not involve the reactivation of old normal faults as reverse faults, though this latter mechanism certainly does occur in places [Stoneley, 1982; Roberts, 1989; de Graciansky et al., 1989; Letouzey, 1990]. The region of extensional half graben imaged by the MOIST seismic reflection line north of Scotland (see Figure 8 and Brewer and Smythe, [1984]) may have been uplifted by lower crustal flow. In this region the Moho is approximately the same depth as it is under Scotland. There is no apparent postrift subsidence above the half graben, whose uppermost synrift infill of Permo-Triassic sediments is found almost at the surface [Kirton and Hitchen, 1987]. Clearly, lower crustal flow has occurred here and has removed any crustal thickness contrast between Scotland and offshore. However, the PermoTriassic sediments are continental or lacustrine [Ziegler, 1982], so the lack of postrift sediments may be because the Permo-Triassic (or older) extension occurred above sea level in thickened crust that subsided at the end of the Caledonian orogeny [McClay et al., 1986]. Flow may have occurred at this time, as the Devonian extension was certainly accompanied by intrusive igneous activity [Ziegler, 1982], rather than in the much later PaleoceneEocene igneous episode. Such igneous activity complicates interpretation of the data, since melt will flow into regions where thinning was greatest and thus reduce crustal thickness contrasts in a manner very similar to lower crustal flow. The regional uplift of Scotland is almost certainly due to underplating [White and Lovell, 1997]. The data are thus equivocal, but the contrast is striking between the MOIST area north of Scotland, which was affected by the early Tertiary basaltic volcanism and has also experienced lower crustal flow, and the Central and Viking Graben east of Scotland, where the Permo-Triassic sediments are typically between 3 and 5 $\mathrm{km}$ below the seabed, and the Moho remains elevated (Figure 8).

We can thus envisage two extreme cases. The first case is a situation in which extension is initiated over a rising mantle plume or over a subduction zone, where igneous activity and perhaps also crustal thickening had already reduced the viscosity of the lower crust. Here

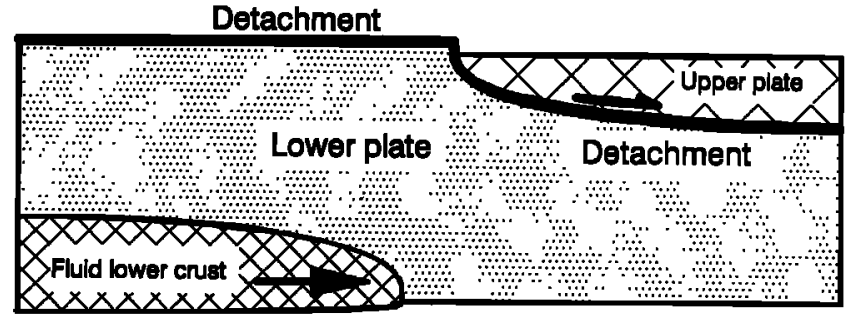

Figure 9. Sketch to show how the spreading of a fluid layer in the lower crust can produce the propagation of a detachment. Rotation of the lower plate occurs as the fluid front passes below. The thickness of the fluid layer must exceed that of the upper plate if this mechanism is to operate. The geometry in the region of the front is not correct in detail.

lower crustal flow could keep pace with upper crustal stretching and prevent the formation of significant long wavelength Moho and surface topography. In the second case, magmatism and flow may follow the inception of stretching by a period that depends on the initial mantle temperature, the amount of stretching, and the strain rate if the magmatism is related to the extension itself [ $M^{c}$ Kenzie and Bickle, 1988] or by an arbitrary period if it is unrelated to extension. In the latter case, deep basins may form during stretching and then be uplifted by the flow.

Figure 9 shows a sketch of the first case, in which the flowing lower crustal layer is simultaneous with extension. As we argue below (section 3.3), there is evidence that, at least in the Basin and Range, this extension takes the form of a throughgoing fault, which in our model is progressively rotated and exhumed as the front propagates. If Figure 9 describes how detachments are uplifted, the thickness of the flowing layer may be estimated from the amount of structural relief seen as the front passes. If the detachment is to reach the Earth's surface, the thickness of the layer of viscous lower crust which is flowing must exceed the thickness of the upper plate. Use of equation (B15) then allows an estimate of the lower crustal viscosity. If mylonites are uplifted from depths of $\sim 10 \mathrm{~km}$ over distances of $\sim 30 \mathrm{~km}$, then the cross-sectional area is $3 \times 10^{8} \mathrm{~m}^{2}$, so that $q=5 \times 10^{7} \mathrm{~m}^{2}, g^{\prime}=10.9 g$ (from equation (B11)), and $x=3 \times 10^{4} \mathrm{~m}$. Then

$$
\dot{x}=6 \times 10^{20} / \eta_{1} \mathrm{~mm} \mathrm{yr}^{-1}
$$

The speed of propagation of such fronts is probably in the region of $10 \mathrm{~mm} \mathrm{yr}^{-1}$ rather than $1 \mathrm{~mm} \mathrm{yr}^{-1}$ or $1 \mathrm{~m} \mathrm{yr}^{-1}$. This argument suggests that $\eta_{1}<6 \times$ $10^{19} \mathrm{~Pa}$ s. Similar values have been derived by Kruse et al. [1991] and Kaufman and Royden [1994].

Such low viscosities may well require a local heat 
source, such as an igneous intrusion. The amount of melt needed to soften the lower crust substantially is easily estimated. Let us assume the lower crust to be at a temperature of $400^{\circ} \mathrm{C}$ and the basaltic intrusion to be at $1200^{\circ} \mathrm{C}$ : an excess of $800^{\circ} \mathrm{C}$. If $3 \mathrm{~km}$ of basalt is intruded, this will raise the temperature of $\sim 9 \mathrm{~km}$ of lower crust by $300^{\circ} \mathrm{C}$. This is enough to induce flow (see section 1) and is compatible with the amounts of melt that can be produced by stretching [see $M^{c}$ Kenzie and Bickle, 1988], particularly if $\beta>2$ or if the upper mantle is hotter than normal. If the reduction in viscosity is due to magmatic addition, the timescale over which the temperature and viscosity of a layer of thickness $10 \mathrm{~km}$ would return to their normal values can be estimated from the usual thermal time constant $\tau_{t h}$ :

$$
\tau_{t h}=a^{2} / \pi^{2} \kappa
$$

where $a$ is the thickness of the layer and $\kappa$ is the thermal diffusivity, to be $\sim 0.5 \mathrm{Myr}$.

\subsection{Detachment Faulting and Tilting in Metamorphic Core Complexes}

Over the last two decades, there has been much debate about the origin of the metamorphic core complexes of the western United States. In these complexes, relatively unmetamorphosed but highly faulted cover rocks of the upper plate are juxtaposed against metamorphosed and penetratively deformed underlying rocks of the lower plate along shallow-dipping faults known as detachment faults [Crittenden et al., 1980].

Lower crustal flow provides a mechanism for rotating the detachment faults in core complexes to shallower dips that does not involve movement on later generations of steep faults. This has been recognized by Gans and Miller [1983], Buck [1988], Wernicke and Axen [1988], Spencer and Reynolds [1990] and Block and Royden [1990], among others. By removing material from beneath unextended horst blocks and repositioning it beneath regions of extended upper crust, large relative vertical motions can occur over a scale of a few tens of kilometers, which in effect, produces tilting of upper crustal rocks. Buck [1988] shows how the upper parts of faults can rotate to shallower dips than their lower parts, thus acquiring a convex-up curvature. He suggests that the flatter, upper parts of the faults become inactive and that new faults form as steeper splays off the deeper part of the fault, cutting through the former hanging wall. In this way flat, inactive faults can be exposed at the surface, though when they were active, they moved in a steeper dip range compatible with seismological observations of active normal faults today [Jackson and White, 1989]. Essential to this mechanism are both a very small effective elastic thickness and flow in the lower crust. Furthermore, the flow must be con- temporary with the faulting. In most of the core complexes of the western United States, there is a strong likelihood that this is the case, as we have already discussed.

It is, however, difficult to understand how the processes discussed above can bring the upper surface of the lower crustal channel to the Earth's surface. The top of the channel is formed by rocks that were originally at midcrustal depths. Most of the shearing occurs by simple shear where the channel thicknesss is uniform and little vertical motion is occurring. Futhermore, this shearing must occur beneath the uplifted plate, since the flow is driven by gravity. The observed structure of core complexes is rather different: the shearing occurs in front of the uplift, and the zone involved is then uplifted. The metamorphic facies of the deformed rocks varies from lower greenschist facies in the upper mylonites to upper greenschist or amphibolite facies at the deepest levels that are exposed [e.g., Lister and Snoke, 1984; Davis, 1983; Davis et al., 1986]. All these features are consistent with the model sketched in Figure 9 , where the detachment is locked onto the propagating front of the lower crustal material but the flowing lower crust does not form the lower plate of the detachment itself.

\section{Conclusions}

We have used simple analytic expressions to investigate the characteristics of flow in a channel that deforms so as to smooth out variations in crustal thickness. These expressions show how variations in density and viscosity affect the length scale and timescale on which flow occurs, and also how the flow is influenced by the boundary conditions on the top and bottom of the channel. The most important results are that the timescale of the flow is very dependent on wavelength, so variations in crustal thickness on a length scale of $\sim 10$ times the channel thickness will decay the most rapidly. As the body of low-viscosity material flows away from regions of thick crust, it does so as a front below a topographic step in the Earth's surface. Under realistic boundary conditions the deformation within the channel will be mainly simple shear. Such a front can drive a detachment fault in front of it, in the same way as marbles on a carpet can be rolled by moving one's hand across the floor underneath.

We also examined the conditions under which lower crustal flow is likely to occur over wavelengths of $100-$ $200 \mathrm{~km}$ in a geologically reasonable time. The strong association of lower crustal flow with areas of both thickened crust and basaltic magmatism suggests that both effects are important in reducing the lower crustal viscosity to a level at which flow is likely. There is evidence 
from parts of the Basin and Range province that the lower crustal flow accompanied the extension of the upper crust, so preventing the development of topographic contrasts between extended and unextended areas at the Earth's surface. The timescale on which such flow occurs puts constraints on the likely viscosity of the lower crustal channel.

If the lower crust flows, it will elevate the depressed, extended areas of the upper crust and lower unextended regions such as horst blocks. Because the channel that flows can be in the region of $10-30 \mathrm{~km}$ thick, it can produce relative vertical displacements of several kilometers in amplitude over distances of a few tens of kilometers. Because it provides a mechanism for tilting that does not require faulting, it may help resolve the discrepancy between the very low angle dips of detachment faults in metamorphic core complexes and the substantially steeper dips seen today in large normal faults that move in earthquakes. Lower crustal flow is also a mechanism by which extended basins can later be uplifted, particularly if the flow occurred after extension had ceased. This mechanism is an alternative to structural inversion by the reactivation of old normal faults as reverse faults, which is also known to occur.

\section{Appendix A: Linear Theory}

In general, any disturbance to either the top or the bottom of the layer generates a flow that moves both. The equations are linear and therefore have solutions of the form $\exp (\sigma t) f(x, z)$, where $\sigma$ may be complex. The interface conditions are that both components of the velocity and the normal and tangential stress must be continuous and that the rate at which any interface moves must equal the normal velocity. This kinematic boundary condition is conveniently combined with the normal stress condition. The problem then reduces to finding the roots of a function that is quadratic in $\sigma$ (see below). The solutions are found to be real for all values of the horizontal wavenumber $k$.

The creeping flow of an incompressible viscous fluid in the absence of buoyancy forces is governed by

$$
\nabla \cdot \mathbf{v}=\mathbf{0}
$$

and by the curl of Stokes's equation

$$
\nabla^{2} \omega=0
$$

where $\omega=\nabla \times \mathbf{v}$ is the vorticity. If the flow is twodimensional in the $x, z$ plane, $\mathbf{v}(=(u, 0, w))$ can be described by a stream function $\Psi$ :

$$
\mathbf{v}=\left(-\frac{\partial \Psi}{\partial z}, 0, \frac{\partial \Psi}{\partial x}\right)
$$

The velocity $\mathbf{v}$ then satisfies (A1) and (A2) if

$$
\nabla^{4} \Psi=0 .
$$

If $\Psi$ is expanded in a Fourier series

$$
\Psi=\psi \sin k x
$$

then

$$
\psi=(A+B z) e^{k z}+(C+D z) e^{-k z},
$$

where $A, B, C$, and $D$ are constants.

Boundary conditions are imposed on $u, w$ and the shear stress $\sigma_{x z}$ using

$$
\begin{gathered}
u=\quad-[k A+(1+k z) B] e^{k z} \sin k x \\
+[k C-(1-k z) D] e^{-k z} \sin k x \\
w=k \psi \cos k x \\
\sigma_{x z}= \\
\quad-2 \eta\left[k^{2} A+k(1+k z) B\right] e^{k z} \sin k x \\
-2 \eta\left[k^{2} C-k(1-k z) D\right] e^{-k z} \sin k x,
\end{gathered}
$$

where $\eta$ is the dynamic viscosity.

The kinematic boundary condition requires the velocity on any boundary to equal the rate at which the boundary deforms. If any such surface is described by $d+\xi$, where $d$ is constant, then

$$
\frac{d \xi}{d t}=\frac{\partial \Psi}{\partial x} \text {. }
$$

If we assume that the decay is exponential with a time constant $\tau$ (which is not necessarily real), then

$$
\xi=\xi_{0} \exp (-t / \tau)
$$

Continuity of normal stress on $z=h$ requires $\sigma_{z z}$ to be continuous, where

$$
\sigma_{z z}=\rho g \xi-P_{1}+2 \eta \frac{\partial w}{\partial z},
$$

where $P_{1}$ is the pressure perturbation due to the flow. We can now use (A10) to eliminate $\xi$ from (A12), and express $P_{1}$ and $w$ in terms of $\psi$ :

$$
\sigma_{z z}=\left(k \tau \rho g \psi+3 k \eta \frac{d \psi}{d z}-\frac{\eta}{k} \frac{d^{3} \psi}{d z^{3}}\right) \sin k x
$$

and $\rho$ is the density of the fluid. If $h$ is the thickness of the layer, (A7)-(A13) may be made dimensionless by substituting

$$
(x, z)=h\left(x^{\prime}, z^{\prime}\right), \quad \tau=\frac{\eta_{1}}{\rho_{1} g h} \tau^{\prime}, \quad k=k^{\prime} / h
$$

where $\rho_{1}$ is the density and $\eta_{1}$ the viscosity of the layer.

The model then requires $A, B, C$, and $D$ to be calculated for the layer and the half-space, $z^{\prime}<-1$. Since the velocity must tend to zero as $z \rightarrow-\infty, C$ and $D$ for the lower layer must be zero. On the upper surface of the layer, $z^{\prime}=0, \sigma_{x z}^{\prime}$ and $\sigma_{z z}^{\prime}$ are required to be zero. The last four conditions are provided by the requirement that $u^{\prime}$ and $\sigma_{z z}^{\prime}$ should be continuous on $z^{\prime}=-1$, and either by continuity of $\sigma_{x z}^{\prime}$ and $u^{\prime}$ or by $u^{\prime}=0$ for both the layer and the half-space. The first of these cases requires that 


$$
\begin{array}{|cc}
\tau-2 k & 0 \\
k & 1 \\
(r-1) k e^{-k} & (r-1)(1-k) e^{-k} \\
{[\tau(R-1)-2 k(r-1)] e^{-k}} & -[\tau(R-1)-2 k(r-1)] e^{-k} \\
& =0
\end{array}
$$

The second is the rigid boundary condition and requires that

$$
\begin{array}{|cc}
\tau-2 k & 0 \\
k & 1 \\
k e^{-k} & (1-k) e^{-k} \\
{[\tau(R-1)-2 k(r-1)] e^{-k}} & -[\tau(R-1)-2 k(r-1)] e^{-k} \\
& =0
\end{array}
$$

where the primes have been omitted and

$$
\eta_{2}=r \eta_{1}, \quad \rho_{2}=R \rho_{1}
$$

where the subscripts 1 and 2 refer to the layer and half-space, respectively. Clearly, (A15) and (A16) are quadratic in $\tau$, and therefore there are two decay times for the model. When $k^{\prime} \gg 1$, the equations are easily solved because the movement of the upper surface, $z^{\prime}=0$, does not affect the shape of the interface $z^{\prime}=-1$, and vice versa. Hence the decay time for disturbances of the upper surface can be found by requiring $C$ and $D$ to be zero in the layer and $\Psi=0$ in the half-space. There is then only one value of $\tau^{\prime}$ that satisfies the equations

$$
\tau_{a}^{\prime}=2 k^{\prime}
$$

or

$$
\tau_{a}=2 \eta_{1} k / \rho_{1} g=4 \pi \eta_{1} / \rho_{1} g \lambda .
$$

Similarly, setting $A=B=0$ in the layer gives

$$
\tau_{b}^{\prime}=2 k^{\prime}(r+1) /(R-1)
$$

or

$$
\tau_{b}=\frac{2 k\left(\eta_{1}+\eta_{2}\right)}{\left(\rho_{2}-\rho_{1}\right) g}=\frac{4 \pi\left(\eta_{1}+\eta_{2}\right)}{\left(\rho_{2}-\rho_{1}\right) g \lambda}
$$

Equations (A18) and (A19) are the solutions to both (A15) and (A16) when $k^{\prime} \rightarrow \infty$. The time $\tau_{b}$ is only positive when $\rho_{2}>\rho_{1}$. When $\rho_{2}<\rho_{1}$, the model is gravitationally unstable, and any disturbance grows exponentially. A finite amplitude model of such an instability, with nonlinear rheology is discussed by Bott [1999]. The other limiting case, $k^{\prime} \ll 1$, is harder to calculate. Two cases are of interest. When $\eta_{2}=0$, (A15) gives

$$
\begin{aligned}
\tau_{a}^{\prime} & =k^{\prime 4} / 3 R, \\
\tau_{a}=\eta_{1} h^{3} k^{4} / 3 \rho_{2} g & =16 \pi^{4} \eta_{1} h^{3} / 3 \rho_{2} g \lambda^{4}, \\
\tau_{b}^{\prime}=4 R /(R-1), \quad \tau_{b} & =4 \eta_{1} \rho_{2} / \rho_{1}\left(\rho_{2}-\rho_{1}\right) g h .
\end{aligned}
$$

If $u$ is zero on the interface, the corresponding expressions from (A16) are

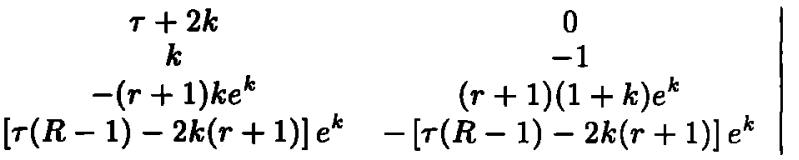$$
-[\tau(R-1)-2 k(r+1)] e^{k}
$$

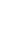

$$
\begin{array}{cc}
\tau+2 k & 0 \\
k & -1 \\
-k e^{k} & (1+k) e^{k} \\
{[\tau(R-1)-2 k(r+1)] e^{k}} & -[\tau(R-1)-2 k(r+1)] e^{k}
\end{array}
$$$$
\longrightarrow
$$

$$
\begin{gathered}
\tau_{a}^{\prime}=4 k^{4} / 3 R \\
\tau_{a}=4 \eta_{1} h^{3} k^{4} / 3 \rho_{2} g=64 \pi^{4} \eta_{1} h^{3} / 3 \rho_{2} g \lambda^{4} \\
\tau_{b}^{\prime}=3 R / k^{2}(R-1) \\
\tau_{b}=\frac{3 \eta_{1} \rho_{2}}{\rho_{1}\left(\rho_{2}-\rho_{1}\right) g h^{3} k^{2}}=\frac{3 \eta_{1} \rho_{2} \lambda^{2}}{4 \pi^{2} \rho_{1}\left(\rho_{2}-\rho_{1}\right) g h^{3}} .
\end{gathered}
$$

The general expressions (A15) and (A16) were solved by iteration, starting with the largest value of $k^{\prime}$ and using (A18) and (A19) as trial values for $\tau_{a}^{\prime}$ and $\tau_{b}^{\prime}$. The resulting values were used as the trial values for the next smaller value of $\boldsymbol{k}^{\prime}$.

A useful quantity known as the admittance $Z$ can be calculated directly from the geophysical observations is the ratio of the gravity anomaly to the surface deformation at a particular wavenumber. It is given by

$$
Z\left(k^{\prime}\right)=\frac{3 g \rho_{1}}{2 a \rho_{e}}\left(1+(R-1) \frac{\xi_{2}^{\prime}}{\xi_{1}^{\prime}} e^{-k^{\prime}}\right),
$$

where $a$ is the radius of the Earth, $\rho_{e}$ the mean density of the Earth, and $\xi_{1}, \xi_{2}$ are the deformation of the upper and lower surfaces of the layer, respectively, obtained from (A10). The curves in Figure $6 \mathrm{c}$ are calculated using $\rho_{1}=2.8 \mathrm{Mg} \mathrm{m}^{-3}, \quad \rho_{e}=5.5 \mathrm{Mg} \mathrm{m}^{-3}$.

\section{Appendix B: Nonlinear Theory}

The expressions given by Huppert [1982] are easily adapted to the case of a lighter liquid spreading over a denser layer, with $u=0$ on the interface. If the upper surface of the layer is $h(x)$ and its thickness is $a(x)$, then if the shear stress vanishes on $z=h(x)$,

$$
(\partial u / \partial z)_{z=h}=0 .
$$

If the horizontal velocity is zero on the lower boundary of the layer,

$$
(u)_{z=h-a}=0 \text {. }
$$

The distance of the lower boundary of the spreading layer below the surface of the liquid half-space is 
$a(x)-h(x)$. Since the layer is thin, the viscous contribution to the normal stress can be neglected, and the boundary condition on $\sigma_{z z}$ at the base of the layer requires that the pressure in the two fluids should be the same. Therefore

$$
g \rho_{1} a=g \rho_{2}(a-h)
$$

or

$$
a=\frac{\rho_{2}}{\rho_{2}-\rho_{1}} h=\frac{R}{R-1} h,
$$

where $R=\rho_{2} / \rho_{1}>1$. Huppert [1982] shows that the balance between the pressure gradient and the viscous forces requires that

$$
\frac{\partial h}{\partial x}=\frac{\eta_{1}}{\rho_{1} g} \frac{\partial^{2} u}{\partial z^{2}}
$$

Integration, subject to (B1) and (B2), then gives

$$
u=\frac{\rho_{1} g}{2 \eta_{1}}\left(z^{2}-2 h z-\left(f^{2}+2 f\right) h^{2}\right) \frac{\partial h}{\partial x},
$$

where

$$
f=\frac{\rho_{1}}{\rho_{2}-\rho_{1}}=\frac{1}{R-1} .
$$

Volume conservation requires that the rate of change of the layer thickness should correspond to the horizontal gradient of the volume flux, or

$$
\frac{\partial a}{\partial t}+\frac{\partial}{\partial x}\left(\int_{-f h}^{h} u d z\right)=0 .
$$

Integration gives Huppert's [1982] equation 2.9:

$$
\frac{\partial h}{\partial t}-\frac{\rho_{1} g^{\prime}}{3 \eta_{1}} \frac{\partial}{\partial x}\left(h^{3} \frac{\partial h}{\partial x}\right)=0,
$$

if $g^{\prime}$ in his equation is given by

$$
g^{\prime}=(1+f)^{2} g .
$$

If the upper boundary of the layer is rigid, (B1) must be replaced by

$$
(u)_{z=h}=0 \text {, }
$$

and (B9) must be replaced by

$$
g^{\prime}=\frac{(1+f)^{2}}{4} g=\frac{R^{2}}{4(R-1)^{2}} g .
$$

Huppert gives similarity solutions to (B8) when

$$
\left(\frac{R-1}{R}\right) \int_{0}^{x_{N}(t)} a(x, t) d x=\int_{0}^{x_{N}(t)} h(x, t) d x=q t^{\alpha},
$$

where $x_{N}$ is given by (B14) with $\nu=\nu_{N}$. If $\alpha=0$ the cross sectional area of the upper layer is $R q /(R-1)$ and constant. The height $h$ then satisfies

$$
h=\left(\frac{3 \nu_{N}^{2}}{10}\right)^{1 / 3}\left(\frac{3 q^{2} \eta_{1}}{\rho_{1} g^{\prime} t}\right)^{1 / 5}\left[1-\left(\nu / \nu_{N}\right)^{2}\right]^{1 / 3}
$$

where

$$
\begin{gathered}
\nu=\left(\frac{3 \eta_{1}}{\rho_{1} g^{\prime} q^{3} t}\right)^{1 / 5} x \\
\nu_{N}=1.411 \ldots
\end{gathered}
$$

The velocity $V_{F}$ with which the front travels can be obtained from (B14):

$$
d \nu=0=\left(\frac{\partial \nu}{\partial t}\right)_{x} d t+\left(\frac{\partial \nu}{\partial x}\right)_{t} d x
$$

Hence

$$
V_{F}=-\frac{(\partial \nu / \partial t)_{x}}{(\partial \nu / \partial x)_{t}}=\frac{\rho_{1} g^{\prime} q^{3} \nu_{N}^{5}}{15 \eta_{1} x^{4}}
$$

Acknowledgments. This work was supported by Natural Environment Research Council and the Royal Society. Earth Sciences contribution 5856.

\section{References}

Barton, P.J., and R.J. Wood, Tectonic evolution of the North Sea basin: Stretching and subsidence, Geophys. J. R. Astron. Soc., 87, 195-208, 1984.

Bellon, H., J.-J. Jarrige, and D. Sorel, Les activités magmatiques égéennes de l'Oligocène à nos jours et leurs cadres géodynamiques: Données nouvelles et synthèse, Rev. Géol. Dyn. Géogr. Phys., 21, 41- 55, 1979.

Bird, P., Lateral extrusion of lower crust from under high topography, in the isostatic limit, J. Geophys. Res., 96, 10,275-10,286, 1991.

Block, L., and L.H. Royden, Core complex geometries and regional scale flow in the lower crust, Tectonics, 9, 557$567,1990$.

Bois, C., and ECORS Scientific Party, Major geodynamic processes studied from ECORS deep seismic profiles in France and adjacent areas. Tectonophysics, 173, 397-410, 1990.

Bott, M.H.P., Modeling local crustal isostasy caused by ductile flow in the lower crust, J. Geophys. Res., 104, 20,34920,359, 1999.

Bott, M.H.P., and D.S. Dean, Stress systems at young continental margins, Nature, 235, 23-25, 1972.

Brewer, J.A., and D.K. Smythe, MOIST and the continuity of crustal reflector geometry along the CaledonianAppalachian orogen, J. Geol. Soc. London, 141, 105-120, 1984

Buck, R., Flexural rotation of normal faults, Tectonics, 5, 959-973, 1988

Coney, P.J., and T.A. Harms, Cordilleran metamorphic core complexes: Cenozoic extensional relics of Mesozoic compression, Geology, 12, 550-554, 1984.

Crittenden, M.D., Jr., P.J. Coney, and G.H. Davis (Eds.), Cordilleran metamorphic core complexes, Mem. Geol. Soc. Am., 153, 1980.

Davis, G.A., Rapid upward transport of mid-crustal mylonitic gneisses in the footwall of a Miocene detachment fault, Whipple Mountains, southeastern California, Geol. Rundschau, 77, 191-209, 1988.

Davis, G.A., G.S. Lister, and S.J. Reynolds, Structural evolution of the Whipple and South Mountains shear zones, southwestern United States, Geology, 14, 7-10, 1986.

Davis, G.H., Shear-zone model for the origin of metamorphic core complexes, Geology, 11, 342-347, 1983.

de Graciansky, P.C., G. Dardeau, M. Lemoine, and P. Tricart, The inverted margin of the French Alps and foreland basin inversion, in Inversion Tectonics, edited by M.A. 
Cooper and G.D. Williams, Spec. Publ. Geol. Soc. London, 44, 87-104, 1989.

England, P.C., and J. Jackson, Active deformation of the continents, Annu. Rev. Earth Planet. Sci., 17, 197-226, 1989.

England, P.C., and D. $\mathrm{M}^{\mathrm{c}}$ Kenzie, $\mathrm{A}$ thin viscous sheet model for continental deformation, Geophys. J. R. Astron. Soc., $70,295-321,1982$.

Fielding, E., B. Isacks, M. Barazangi, and C. Duncan, How flat is Tibet?, Geology, 22, 163-167, 1994.

Fuis, G.S., W.D. Mooney, J.H. Healy, G.A. McMechan, and W.J. Lutter, A seismic refraction survey of the Imperial Valley region, California, J. Geophys. Res., 89, 11651189, 1984.

Gans, P.B., An open-system, two layer crustal stretching model for the eastern Great Basin, Tectonics, 6, 1-12, 1987.

Gans, P.B., and E.L. Miller, Style of mid-Tertiary extension in east-central Nevada, in Geologic Excursions in the Overthrust Belt and Metamorphic Core Complexes of the Intermountain Region, Nevada, Geol. Soc. Am. Field Trip Guide Utah Geol. Miner. Surv. Spec. Stud., vol. 59, pp. 107-160, Geol. Soc. of Am., Boulder, Colo., 1983.

Gans, P.B., G.A. Mahood, and E. Schermer, Synextensional magmatism in the Basin and Range province: A case study from the eastern Great Basin, Geol. Soc. Am. Spec. Paper, 233, 53 pp., 1989.

Ginzburg, A., R.B. Whitmarsh, D.G. Roberts, L. Montadert, A. Camus, and F. Avedik, The deep seismic structure of the northern continental margin of the Bay of Biscay, Ann. Geophys., 3, 499-510, 1985.

Glazner, A.F., J.E. Nielson, K.A. Howard, and D.M. Miller, Correlation of the Peach Springs Tuff; a large-volume Miocene ignimbrite sheet in California and Arizona, Geology, 14, 840-843, 1986.

Gratton, J., Crustal shortening, root spreading, isostasy, and the growth of orogenic belts: A dimensional analysis, J. Geophys. Res., 94, 15,627-15,634, 1989.

Holliger, K., and S.L. Klemperer, A comparison of the Moho interpreted from gravity data and from deep seismic reflection data in the northern North Sea, Geophys. J., 97. 247-258, 1989.

Hopper, J.R., and W.R. Buck, The effect of lower crustal flow on continental extension and passive margin formation, J. Geophys. Res., 101, 20,175-20,194, 1996.

Huppert, H.E., The propagation of two-dimensional and axisymmetric gravity currents over a rigid horizontal surface, J. Fluid Mech., 121, 43-58, 1982.

Jackson, J.A., and N.J. White, Normal faulting in the upper continental crust: Observations from regions of active extension, J. Struct. Geol., 11, 15-36, 1989.

Jackson, J.A., N.J. White, Z. Garfunkel, and H. Anderson, Relations between normal fault geometry, tilting and vertical motions in extensional terrains: An example from the southern Gulf of Suez, J. Struct. Geol., 10, 155-170, 1988.

James, D.E., T.J. Smith, and J.S. Steinhart, Crustal structure of the middle Atlantic states, J. Geophys. Res., 73, 1983-2007, 1968.

Kaufman, P.S., and L.H. Royden, Lower crustal flow in an extensional setting: constraints from the Halloran Hills region, eastern Mojave desert, California, J. Geophys. Res., $99,15,723-15,739,1994$.

Kirton, S.R., and K. Hitchen, Timing and style of crustal extension $N$ of the Scottish mainland, in Continental $E_{x}$ tensional Tectonics, edited by M.P. Coward, J.F. Dewey, and P.L. Hancock, Spec. Publ. Geol. Soc. London, 28, 501-510, 1987.
Kruse, S., M. McNutt, J. Phipps-Morgan, L. Royden, and B. Wernicke, Lithospheric extension near Lake Mead, Nevada: a model for ductile flow in the lower crust, $J$. Geophys. Res., 96, 4435-4456, 1991.

Kusznir, N.J., and D.H. Matthews, Deep seismic reflections and the deformational mechanics of the continental lithosphere, J. Petrol., Special Lithosphere Issue, 63-87, 1988.

Letouzey, J., Fault reactivation, inversion and fold-thrust belt, in Petroleum and Tectonics in Mobile Belts, edited by J. Letouzey, pp. 101-128, Technip, Paris, 1990.

Lister, G.S., and A.W. Snoke, S-C mylonites, J. Struct. Geol., 6, 617-638, 1984.

Makris, J., and C. Stobbe, Physical properties and state of the crust and upper mantle of the eastern Mediterranean Sea deduced from geophysical data, Mar. Geol., 55, 347$363,1984$.

McClay, K.R., M.G. Norton, P. Coney, and G.H. Davis, Collapse of the Caledonian orogen and the Old Red Sandstone, Nature, 323, 147-149, 1986.

$\mathrm{M}^{\mathrm{c}}$ Kenzie, D., Gravity currents in the lower crust (abstract), Geol. Soc. Newsl., 17, 12, 1988.

$M^{c}$ Kenzie, D., and M.J. Bickle, The volume and composition of melt generated by extension of the lithosphere, $J$. Petrol., 29, 625-679, 1988.

Meissner, R., and N.J. Kusznir, Crustal viscosity and the reflectivity of the lower crust, Ann. Geophys., Ser. B, 5, 365-374, 1987.

Meissner, R., D.H. Matthews, and T. Wever, The "Moho" in and around Great Britain, Ann. Geophys., Ser. B, 4, 659-664, 1986.

Mercier, J.L., D. Sorel, P. Vergely, and K. Simeakis, Extensional tectonic regimes in the Aegean basins during the Cenozoic, Basin Res., 2, 49-71, 1989.

Nakada, M., Convective coupling between ductile lower crust and upper mantle, and its tectonic implications, Geophys. J. Int., 118, 579-603, 1994.

Nielson, J.E., and K.K. Beratan, Tertiary basin development and tectonic implications, Whipple detachment system, Colorado River extensional corridor, California and Arizona, J. Geophys. Res., 95, 599-614, 1990.

Nielson, J.E., D.R. Lux, G.B. Dalrymple, and A.F. Glazner, Age of the Peach Springs Tuff, southeastern California and western Arizona, J. Geophys. Res., 95, 571-580, 1990.

Roberts, D.G., Basin inversion in and around the British Isles, in Inversion Tectonics, edited by M.A. Cooper and G.D. Williams, Spec. Publ. Geol. Soc. London, 44, 131152, 1989.

Royden, L., Coupling and decoupling of crust and mantle in convergent orogens: implications for strain partitioning in the crust, J. Geophys. Res., 101, 17,679-17,705, 1996.

Smith, R.B., Unified theory of the onset of folding, boudinage, and mullion structure, Bull. Geol. Soc. Am., 86, 1601-1609, 1975.

Solomon, S.C., R.P. Cormer, and J.W. Head, The evolution of impact basins: Viscous relaxation of topographic relief, J. Geophys. Res., 87, 3975-3992, 1982.

Spencer, J.E., and S.J. Reynolds, Relationship between Mesozoic and Cenozoic tectonic features in west-central Arizona and adjacent southeastern California, J. Geophys. Res., 95, 539-555, 1990.

Stocker, R.L., and M.F. Ashby, On the rheology of the upper mantle, Rev. Geophys., 11, 391-426, 1973.

Stoneley, R., The structural development of the Wessex basin, J. Geol. Soc. London, 139, 543-554, 1982.

Strehlau, J., and R. Meissner, Estimation of crustal viscosities and shear stresses from an extrapolation of experimental steady state flow data, in Composition, Structure and Dynamics of the Lithosphere-Asthenosphere System, 
Geodyn. Ser., vol. 16, edited by K. Fuchs and C. Froidevaux, pp. 69-87, AGU, Washington D.C., 1987.

Taymaz, T., J.A. Jackson, and D. M Kenzie, Active tectonics of the north and central Aegean Sea, Geophys. J. Int., 106, 433-490, 1991.

Watson, J., The ending of the Caledonian orogeny in Scotland, J. Geol. Soc. London, 141, 193-214, 1984.

Wernicke, B.P., and G. Axen, On the role of isostasy in the evolution of normal fault systems, Geology, 16, 848-851, 1988.

White, N., and B. Lovell, Measuring the pulse of a plume with the sedimentary record, Nature, 287, 888-891, 1997.

Yielding, G., Footwall uplift associated with late Jurassic normal faulting in the northern North Sea, J. Geol. Soc. London, 147, 219-222, 1990.

Young, R.A., and W.J. Brennan, The Peach Springs Tuffits bearing on the structural evolution of the Colorado Plateau and development of Cenozoic drainage in Mohave County, Arizona, Bull. Geol. Soc. Am., 85, 83-90, 1974.

Zhao, W., and J.W. Morgan, Injection of Indian crust into Tibetan lower crust: A two-dimensional finite element model study, Tectonics, 6, 489-504, 1987.
Zhong, S., Dynamics of crustal compensation and its influences on crustal isostasy, J. Geophys. Res., 102, 15,28715,299, 1997.

Ziegler, P., Geological Atlas of Western and Central Europe, 130 pp., Elsevier Sci., New York, 1982.

P.B. Gans, Department of Geological Sciences, University of California, Santa Barbara, CA 93106-9630. (gans@magic.ucsb.edu)

J.A. Jackson, D. M'Kenzie, and F. Nimmo, Bullard Laboratories, Madingley Road, Cambridge CB3 0EZ, England, U.K. (jackson@esc.cam.ac.uk; mckenzie@esc.cam.ac.uk; nimmo@esc.cam.ac.uk)

E.L. Miller, Department of Geological and Environmental Sciences, Building 320, Stanford University, Stanford, CA 94305. (miller@pangea.stanford.edu)

(Received May 5, 1999; revised November 2, 1999; accepted December 17, 1999.) 